\title{
One-dimensional titanate nanotube materials: heterogeneous solid catalysts for sustainable synthesis of biofuel precursors/value-added chemicals-a review
}

\author{
Aderemi Timothy Adeleye $e^{1,2,3, *}$ (1), Kingsley I. John ${ }^{1,2,3,4}$, Promise Goodness Adeleye ${ }^{5}$, \\ Amos Adeleke Akande ${ }^{6,7}$, and Oluwakemi Oluwabunmi Banjoko ${ }^{8}$ \\ ${ }^{1}$ Dalian Institute of Chemical Physics, Chinese Academy of Sciences, Dalian 116023, China \\ ${ }^{2}$ University of Chinese Academy of Sciences, 19 A Yuquan Road, Shijingshan District, Beijing 100049, China \\ ${ }^{3}$ Organization of African Academic Doctor (OAAD), Off Kamiti Road, P. O. Box 25305000100, Nairobi, Kenya \\ ${ }^{4}$ Lab of Department of Pure and Applied Chemistry, College of Natural Sciences, Veritas University Abuja, PMB 5171, Abuja, Nigeria \\ ${ }^{5}$ Department of Agriculture, University of Ilorin, P. M. B. 1515, Ilorin, Nigeria \\ ${ }^{6}$ CSIR NextGen Enterprises and Institutions Cluster, EDT4IR Research Centre, P O Box 395, Pretoria 0001, South Africa \\ ${ }^{7}$ Department of Physics, University of Limpopo, P/Bag X1106, Sovenga 0727, South Africa \\ ${ }^{8}$ Department of Chemical Sciences, Tai Solarin University of Education, Ogun State, ljagun, Nigeria
}

Received: 22 May 2021

Accepted: 24 August 2021

Published online:

5 September 2021

(C) The Author(s), under exclusive licence to Springer Science+Business Media, LLC, part of Springer Nature 2021

\begin{abstract}
One-dimensional (1D) titanate nanotubes materials (protonated titanate nanotube (HTNT) and sodium titanate nanotube (NaTNT)) have been reported as low-cost and efficient catalytic materials in chemical syntheses for the production of biofuel precursors with interesting catalytic performance exhibited, even better than some commonly used zeolites, H-MOR, $\mathrm{H}-\beta, \mathrm{SO}_{4}{ }^{2-} / \mathrm{Al}_{2} \mathrm{O}_{3}$, and H-ZSM-5 solid catalysts with environmental benign in focus when compared with homogeneous catalytic materials. This mini-review expressly revealed the significance and potential of using HTNT and NaTNT as sustainable and environmentally benign solid catalysts/supports in various chemical reactions. The critical assessment of biomass valorization and titanate nanostructured materials as catalysts/supports via Green Chemistry approach, \#7 (use of renewable feedstocks), \#9 (use of catalyst against stoichiometry) and United Nations (UN) Sustainable Development Goals (SDGs), \#7 (affordable and clean energy; ensure access to inexpensive, reliable, sustainable, and new energy), is presented as integrated pathways to meet environmental benign technology toward sustainability. Hence, this work follows in the pattern of recent formulated features reported for solid catalysts-'PYSSVR' concept, which means P-production cost, Y-yield, S-stability, S-selectivity, V-versatility, and R-reusability.
\end{abstract}

Handling Editor: Christopher Blanford.

Address correspondence to E-mail: aderemi4crown@yahoo.com 


\section{GRAPHICAL ABSTRACT}

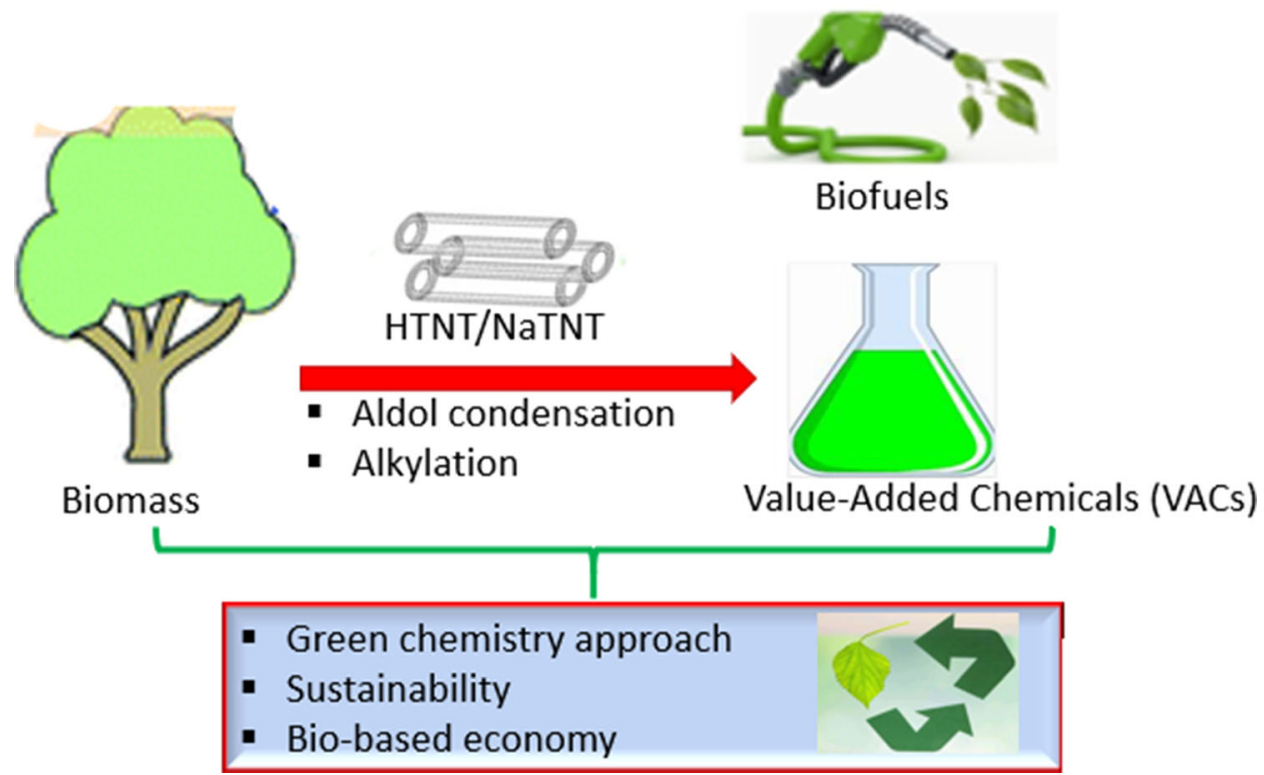

\section{Introduction}

\section{Abbreviations}

HTNT Protonated titanate nanotubes

NaTNT Sodium titanate nanotubes

STNTs Sodium titanate nanotubes

VACs Value-added chemicals

BBE Bio-based economy

VAPs Value-added products

LA Levulinic acid

PHAs Polyhydroxyalkanoates

AC Activated carbon

LAS Lewis acid sites

BAS Brønsted acid sites

SACs Solid acid catalysts

HMF 5-Hydroxymethylfurfural

TOF Turn-over frequency

HAA Hydroxyalkylation/alkylation

PTNW Protonated titanate nanowire

BHET Bis(hydroxyethyl)terephthalate

a- $\mathrm{TiO}_{2}$ The amorphous $\mathrm{TiO}_{2}$

SDGs Sustainable Development Goals
As long as economic and socioeconomic developments become the priority of every nation of the world with rapid population growth, the quest for global energy needs will also be in high demand. Recently, the transportation sector has recorded huge consumption of liquid hydrocarbon contents and fuel additives. Majorly, most of these consumptions come from non-renewable petroleum resources. As a frontline sector, transport with remarkable growth has attracted high demand for oil supply. The sudden emerging economic advancement of countries like China and India has also hugely contributed to global fuel consumption [1-5]. With the high consumption of non-renewable petroleum resources, a rise in $\mathrm{CO}_{2}$ emissions is inevitable [6]. Therefore, there is an urgent need that obliges new chemical technology protocols to convert naturally plentiful biomass to renewable transportation fuels, and value-added chemicals (VACs) toward achieving a bio-based economy (BBE) [1, 2].

Recently, many research activities have been concentrated on utilizing biomass due to the likelihood 
of serving as a substitute for the viable formation of fuels and chemicals [5]. Apart from liquid hydrocarbon fuels obtainable from renewable feedstocks, countless numbers of value-added products (VAPs) have also been synthesized; among them are levulinic acid (LA) [6] and polyhydroxyalkanoates (PHAs) which have been used in various applications such as in biodiesel production as precursors and production of biopolymers [7] and activated carbon (AC).

This sustainable material has also found useful applications in catalysis, environmental remediation [1], etc. To address the shortcomings of conventional petroleum resources, loads of attention and efforts have been made in the direction of catalytic transformation of renewable precursors to either fuel intermediates or value-added chemicals (VACs) and/or fuels. Technically and economically, with the abundance of biomass on earth, world energy consumptions can adequately be addressed [1, 6, 7]. Thermal, biochemical, and chemical routes are three major pathways to actualize the conversions of renewable feedstocks to fuel intermediates, fuels, and value-added chemicals (VACs) [8, 9]. However, the catalytic conversion pathway is the most effective route for synthesizing biofuels like bioethanol and biogas and value-added chemicals (VACs). For bioeconomy, efficient catalytic biomass transformation technology cannot be overemphasized. According to Alwin Mittasch's statement, "Chemistry without catalysis would be a sword without a handle, a light without brilliance, a bell without sound" [10]. According to the above statement, the active role of sustainable catalytic systems cannot be restrained to successfully attain the quality and value of the final product in biomass transformation $[1,8,9]$.

The first study conducted on the synthesis of nanostructured titanium oxide and titanates by Kasuga et al. has brought these materials to the limelight. Nanostructured titanate materials with special structures and properties, for example, nanosheets, nanotubes, nanowires, and nanorods, have been thoroughly researched in recent years. Though titanium oxides seem to be unpopular compared to carbon nanostructures, they have offered an impressive starting point of the breakthrough due to their low cost and facile synthesis routes that employ the use of existing conventional laboratory scalable protocols [11, 12]. Many works of the literature have described the synthesis of titanate nanotubes by various methods such as hydrothermal treatment
[11-14], sol-gel processes [15], and the anodizing of titanium metal [16-18]. Among various methods previously reported, hydrothermal treatment of titania nanoparticles with aqueous sodium hydroxide solution has received wide utilization, and this study revolves around it [11-14]. These 1D nanostructured materials have piqued interest owing to their peculiar electrical, optical, and mechanical properties, as well as their broad range of applications [17]. Titania's efficiency in various applications is determined by its crystalline phase, dimensions, and morphologies [16-18].

A few reviews have been published on titanate nanostructured derived materials on various applications as highlighted below. However, very few reviews have specifically reported protonated/sodium titanate nanotubes as solid catalysts/supports on the synthesis of renewable fuel intermediates, value-added chemicals (VACs), and renewable liquid hydrocarbon fuel. For example, a review published by Abdullah and his co-workers on titanium dioxide nanotubes (TNTs) described the unique characteristic features and applications of TNTs in various fields such as energy storage devices, sensors, and environmental analysis systems are all examples of photocatalytic systems, [19] with exception to biofuel-derived application. In another recent review, the approaches and principles for the photocatalytic water-splitting process and the preparation and polymorphs of $\mathrm{TiO}_{2}$ nanotubes were presented with combinations of various methods suitable for high photocurrent density with interesting stability [20]. In another study conducted, the authors present an overview of the properties and applications of both titanate-derived nanotubes and nanowires with a sole focus on the elucidation of the surface science related to various fields like heterogeneous catalytic, photocatalytic, photovoltaic, and energy storage utilization [21] with exception to biofuels. In their report, Zhang. $Y$ et. al also presented the unique characteristics features of nanosized $\mathrm{TiO}_{2}-$ derived materials and their applicable use in photocatalysis, adsorption, lithium-ion batteries, photovoltaics, electrochromic devices, self-cleaning, and oil-water separation, while their attributed functional performances were keenly attributed to possession of physicochemical features [22].

The synthesis of titanium dioxide nanotubes utilizing hydrothermal protocol was equally presented in another report given priority to the pathways of 
their formation, the chemistry of the properties, and existing applications in dye-sensitized solar cells, photocatalysis, or as biomedical coatings with exception to biofuels and value-added chemical (VACs). However, the responsible characteristic features for their applications were attributed to existing tubular structures [23]. Giannakoudakis, D. A et.al., also presented a detailed report on the effects of sonochemistry or ball milling technique as a synthesis pathway for zero- or one-dimensional nanostructured-derived titanate materials and application in photocatalysis [24]. Another recent review also presented various applicable methods (such as anodic deposition, sol-gel template synthesis, and alkaline hydrothermal treatment) for the synthesis of TiNTs and the applications of as-synthesized TiNTs in $\mathrm{H}_{2}$ production and methanation, $\mathrm{NO}$ reduction, $\mathrm{CO}$ oxidation, photocatalysis, and organic synthesis [25]. Another excellent review study by Sudarsanam. P et.al, reported utilization of titanium dioxide as a water-tolerant solid catalyst for the transformation of biomass to fuels and renewable chemicals with keen attention and focus on hydrothermal stability of titanium dioxide-derived materials, its estimated acidity, and pathways for the synthesis. This review article represents the most recent work that reported titanate-derived materials as solid catalysts in biomass transformations [26].

With a countless number of review works that have been reported on titanate-derived materials for various applications and a very limited numbers on protonated/sodium titanate nanotubes as sustainable solid catalysts for biomass valorization, there is an urgent need to close this vacuum. Thus, this review would serve as a reference theme to take advantages of one-dimensional (1D) titanate nanostructured catalytic materials in sustainable biorefinery.

In the present review, we aimed to fill the vacuum with clear green credentials of sustainable titanatederived solid catalysts (majorly focus on protonated titanate nanotubes and sodium titanate nanotubes) and utilization of abundant biomass resources as precursors toward bio-based economy (BBE) to unravel their environmental benefits through benign synthesis or eco-friendly technology. The primary goal of bio-based economy (BBE) can only be sustained via clear green credentials of sustainable catalysis and utilization of renewable feedstocks (which do not compete with foods and feeds) following the provision of Green Chemistry's principles and sustainable development goals (SDGs). Therefore, the discussion of this mini-review is tailored to present a comprehensive overview of HTNT and NaTNT as sustainable solid catalysts/supports for the efficient transformation of biomass. However, the presentation of this review will be restricted to the synthesis of one-dimensional (1D) HTNT and NaTNT via a hydrothermal protocol.

The review begins with the introduction and need of renewable liquid hydrocarbon fuels, sustainable use of solid catalysts in the transformation of biomass to fuel intermediates, biofuels, and value-added chemicals toward bio-economy. This is followed by a detailed synthesis of 1D nanostructured NaTNT and HTNT via hydrothermal technology with the elucidation of their existing nanotubular structures and suitability in biomass transformations. Furthermore, various published articles that had explored sodium titanate nanotube and protonated titanate nanotubes as sustainable solid heterogeneous catalysts in biomass transformations were critically analyzed. Finally, the critical assessment of titanate nanostructured materials as catalysts/supports and biomass valorization via Green Chemistry approach, \#7 (use of renewable feedstocks), \#9 (use of catalyst against stoichiometry), and United Nations (UN) Sustainable Development Goals (SDGs), \#7(affordable and clean energy; ensure access to inexpensive, reliable, sustainable, and new energy), is presented as integrated pathways to meet environmental benign technology toward sustainability.

Therefore, an acceleration of this mini-review is considered important due to its ability to decrease the carbon footprint of petroleum-based resources, which will impede the signature of global warming on the planet toward the realization of the bio-economy. To make the work simple and clear to our readers, we, therefore, present different symbols of protonated titanate nanotubes (such as HTNT, PTNT, and HiTNT) and sodium titanate nanotubes (such as NaTiNT, NaTNT, and STNTs) used in various previously published studies. These symbols were equally used according to each referenced article used in this work.

Interestingly, this work follows in the pattern of recent formulated features reported for solid catalysts-'PYSSVR' concept, which means $P$-production cost, Y-yield, S-stability, S-selectivity, V-versatility, and $R$-reusability by Sudarsanam. P et.al [27]. 


\section{One-dimensional (1D) nanostructured titanate materials-the efficient solid acid catalyst of high value!}

Recent advances in nanoscience and nanotechnology have paved the way for more operational, "green," and long-lasting nanostructured catalytic systems. Due to their unique physicochemical properties, for instance, a high surface-to-volume ratio, strong dispersibility, and increased accessibility of surface hydroxyl groups, Lewis acid sites (LAS) and Bronsted acid sites (BAS), 1D HTNT has been established as attractive catalysts and supports [8, 11-13]. Given that nanomaterials are a type of material whose dimensions are described by the nanometer scale (typically ranging from 1 to $100 \mathrm{~nm}$ ) in the field of nanoscience and nanotechnology [28-31], the term "nanostructure" is commonly used to designate the geometrical structure of nanomaterials. Nanostructured titanates materials have got a lot of attention lately, and they have a lot of applications in catalytic systems. Their usage has also been aided by their large surface areas and ion-exchange properties [32]. They also provide a good medium for annealing, which can be used to achieve phase and morphological tailoring [33, 34]. The ion-exchange properties of alkali titanates are appealing. Because of their large specific surface, titanate nanotubes and nanowires are especially interesting [35].

However, this research focuses on the use of $\mathrm{Na}$ / protonated titanate nanotubes for converting biobased platform compounds into biofuel intermediates/VACs. The development of low-cost and effective solid acid catalysts (SACs) that can be used in various catalytic processes is critical, but it is still difficult to come by. As a result, developing a new and economical approach to pollution mitigation must be adopted to implement environmentally sustainable chemical processes. According to Anastas and Warner's 12 philosophies of Green Chemistry [36], green chemistry is one of the most useful and appropriate approaches for pollution reduction. The quest for an environmentally friendly solid acid catalyst is unavoidable to consolidate this advancement in chemical processes. Reduced vessel corrosion, simplicity of product separation, catalyst recovering, and ecological suitability are only a few of the advantages of using a solid acid catalyst instead of a liquid acid catalyst. SACs, such as heteropolyacids, metal oxides (e.g., niobic acid), phosphates, zeolite (e.g., H-Mordenite), and sulfonated resins, have low catalytic performance (e.g., Amberlyst-15, Nafion) $[37,38]$ because of the low density of acid sites, poor stability, and economic implications, they need to be significantly improved. [39, 40].

Herein, we report a series of published works of a new kind of efficient sodium/protonated titanate nanotubes hydrothermally obtained via nanotechnology applications. The current method holds a lot of promise for the future development of new families of cost-effective and reliable solid catalysts on eco-friendly precursors, scalable and sustainable protocols $[1,8,9,12,13]$. The benefits of solid acid catalysts as heterogeneous over homogeneous in chemical industrial transformation processes have been previously reported Hideshi Hattori et al.[41]

\section{Synthesis of titanate nanotubes-why is the hydrothermal method gaining momentum?}

\section{Hydrothermal technique}

Hydrothermal synthesis is one of the most popular methods for making nanomaterials. Hydrothermal synthesis is a method for crystallizing materials (chemical compounds) directly from an aqueous solution by carefully regulating thermodynamic variables including temperature $\left(>100{ }^{\circ} \mathrm{C}\right)$, pressure ( $>1$ atmosphere), and composition. Hydrothermal synthesis is a heterogeneous chemical reaction with many benefits, including low cost, mass efficiency, and high product purity [42]. It is referred to as a "reaction-based solution technique." As it is used, the synthesis and formation of nanomaterials can be carried out at ambient temperatures to extremely high temperatures [43]. Because the vapor pressure of the reaction's main constituent is taken into consideration, the morphology of the desired nanomaterials can be well-balanced or simply regulated using lowpressure or high-pressure conditions. This synthetic technique has got a lot of attention because of the significant advantages it has over others. At high temperatures, hydrothermal synthesis can produce nanomaterials that are unstable. The hydrothermal method can generate nanomaterials with high vapor pressures with negligible material damage. Via liquid phase or multiphase chemical reactions, the 
compositions of nanomaterials to be synthesized can be precisely regulated in the hydrothermal system [43]. The benefits of employing hydrothermal techniques over other techniques (Fig. 1) [43-46]. However, the excess of water employed for washing these titanate materials at washing stage is disadvantaged to system. Furthermore, preparation of the reported titanate-derived materials involves utilization of medium concentration of $\mathrm{NaOH}$; therefore, excessive usage of water is inevitable.

\section{One-dimensional (1D) titanate nanomaterials}

Titanate nanotubes are hollow tubes with exact inner and outer diameters and a wide surface area (ranging from 200 to $480 \mathrm{~m}^{2}$. $\mathrm{g}^{1}$ ) [47]. Nanotubes have several (4-7) walls that are separated by around $1 \mathrm{~nm}$, which corresponds to the $0.96 \mathrm{~nm}\left(\begin{array}{lll}1 & 0 & 0\end{array}\right)$ interplanar gap of $\mathrm{Na}_{2} \mathrm{Ti}_{3} \mathrm{O}_{7}$ [48]. They are made up of manifold (4-7) walls partitioned by about $1 \mathrm{~nm}$, which equals the $0.96 \mathrm{~nm}\left(\begin{array}{lll}1 & 0 & 0\end{array}\right)$ interplanar width, and measure 50-200 nm in length, 4-8 nm inner and 8-15 nm outer diameter. Kasuga et al. [11, 12] announced the hydrothermal treatment of $\mathrm{TiO}_{2}$ nanoparticles using $\mathrm{NaOH}$ (aq) to produce titanate nanotubes. Titanates nanotubes are characterized by cavities, ions that can be exchanged, large internal and external surfaces, and large pore volumes due to the presence of pores along the length and interlay cavities in the walls. They have a tubular, mesoporous structure with a large number of pores. In hollow nanotubes, capillary condensation occurs [49]. Unlike anatase $\mathrm{TiO}_{2}$, this is

Figure 1 Advantages of hydrothermal techniques in materials synthesis, data taken from [43-46]. a multi-walled scroll-type open-ended nanotube with a layered titanate structure comparable to $\mathrm{H}_{2} \mathrm{Ti}_{3} \mathrm{O}_{7}$, $\mathrm{H}_{2} \mathrm{Ti}_{4} \mathrm{O}_{9} \cdot \mathrm{H}_{2} \mathrm{O}, \mathrm{H}_{2} \mathrm{Ti}_{2} \mathrm{O}_{5} \cdot \mathrm{H}_{2} \mathrm{O}$, and $\mathrm{H}_{2} \mathrm{Ti}_{5} \mathrm{O}_{11} \cdot \mathrm{H}_{2} \mathrm{O}$ [33]. The mechanistic reactions during the hydrothermal formation of titanate nanotubes (HTNT) are described by Eqs. 1 and 2. More precisely, Eq. 1 depicts the hydrothermal treatment's conversion of anatase to titanate nanosheets.

The ion-exchange mechanism caused by mild acid washing, on the other hand, is represented by Eq. 2 . As can be shown, NaTNT is transformed to HTNT, which is followed by the creation of nanotubes. According to consensus, dissolving the preliminary $\mathrm{TiO}_{2}$ in a high concentration of aqueous $\mathrm{NaOH}$ solution produced layered sodium titanates nanosheets formed as intermediates that were rolled up into tubular structures, with the nanotubes forming along their axis $[11,12]$.

$$
\begin{aligned}
& 3 \mathrm{TiO}_{2}+2 \mathrm{NaOH} \rightarrow \mathrm{Na}_{2} \mathrm{Ti}_{3} \mathrm{O}_{7}+\mathrm{H}_{2} \mathrm{O} \\
& \mathrm{Na}_{2} \mathrm{Ti}_{3} \mathrm{O}_{7}+2 \mathrm{H}^{+} \rightarrow 2 \mathrm{Na}^{+}+\mathrm{H}_{2} \mathrm{Ti}_{3} \mathrm{O}_{7}
\end{aligned}
$$

Mechanistic formation of nanostructured titanate materials has been widely investigated and justified through many published reports [50-52]. Through characterization, these tubular titanate materials have shown characteristic properties (such as ion-exchange features, interesting specific surface area (SSA) and open mesoporous morphology) that positioned them for various applications in many fields. Furthermore, observed from the walls of TNTs are structure made up of edge- and corner-sharing $\mathrm{TiO}_{6}$ octahedra structure with zigzag characteristic natures which has positioned sodium ions between the

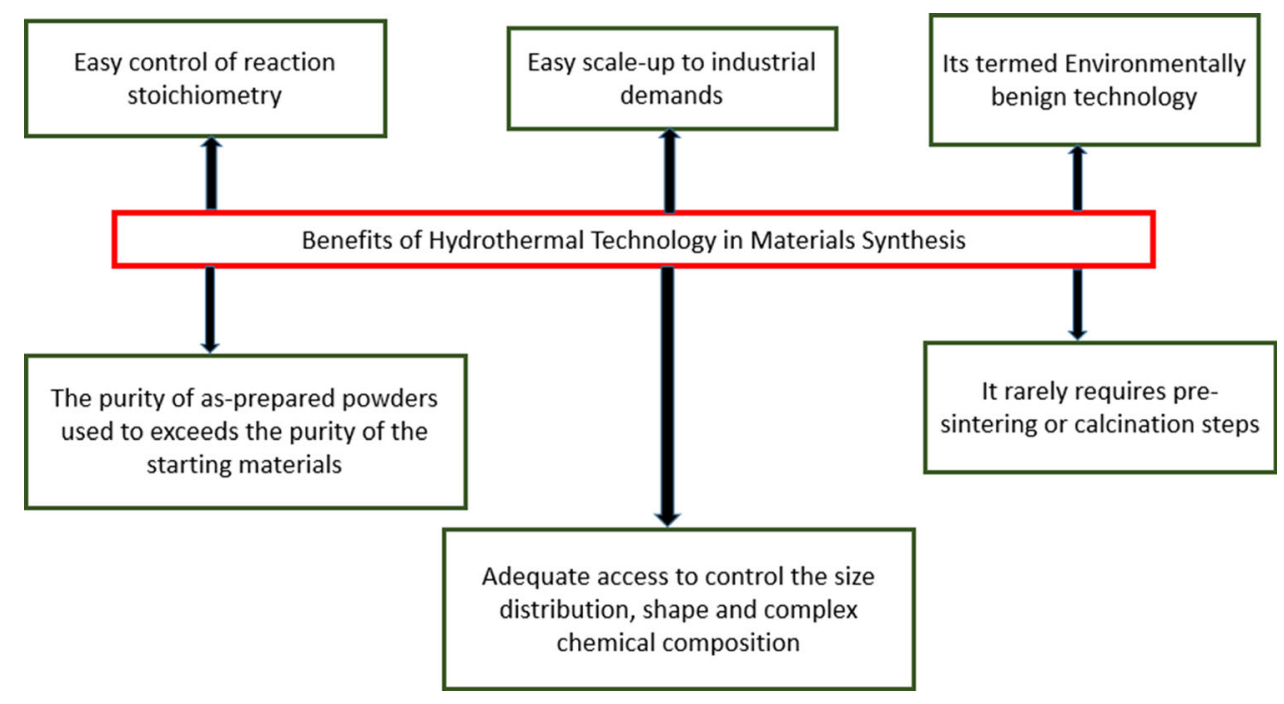


existing $\mathrm{TiO}_{6}$ layers. As earlier reported here PTNT/ NaTNT catalytic materials can however be synthesized by means of a subsequent sodium/proton exchange process. The comprehensive crystal structure of titanate nanotubes seems to be indistinct, nevertheless the widespread generally proposed formula for NaTNT is presumed to be $\mathrm{Na}_{2} \mathrm{Ti}_{3} \mathrm{O}_{7}$, while that of PTNT is $\mathrm{H}_{2} \mathrm{Ti}_{n} \mathrm{O}_{(2 n+1)} \times \mathrm{HH}_{2} \mathrm{O}$ [53]. The versatility of the hydrothermal technique has also been employed to synthesize titanate nanowires because of the advantages of low temperature, onestep processes, and high product purity and homogeneity [54-56]. Another group has developed a method for solution synthesis of $\mathrm{TiO}_{2}$-based long nanowires at temperatures between 160 and 180 degrees Celsius for 1-7 days. This is because short nanotubes are generated by using a shorter reaction time at lower reaction temperatures [57] via titania hydrothermal treatment in a high-concentrated solution potassium hydroxide solution, and Tsumura et al. successfully synthesized titanate nanowires with various diameters and lengths. The diameters of these wires could be adjusted by selecting the appropriate starting precursors titania. Titanate wires may be thicker and longer when larger titania particles with a rutile-like structure are used as the starting material [58].

The overall transformation of raw $\mathrm{TiO}_{2}$ to nanotubular titanate materials, according to Kukovecz A. et al., can be expected to take place in several stages [59]. Figure 2 depicts these stages of formation, while Fig. 3 depicts a soft chemical process of exfoliating- rolling nanotube formation from layered $\mathrm{Na}_{2} \mathrm{Ti}_{3} \mathrm{O}_{7}$ particles, according to Liu R. et al. [60]:

Undeniably, ion exchange is a fundamental fragment of the preparation activity itself, as we know that $\mathrm{Na}^{+}$ions resulted through crystallized nanostructure are substituted with protons via washing stage. When univalent cations are involved in the synthesis, the exchange activity are readily and practically quantitative (with proposed formula $\mathrm{Me}_{\mathrm{x}}$ $\mathrm{H}_{2-\mathrm{x}} \mathrm{Ti}_{3} \mathrm{O}_{7}$, in this case $\mathrm{x}$ can be said to nearly close to 2), while in the case of cations, when positive charges are not univalent in nature, that is involving multiple positive charges, the exchange activity has been pronounced problematic owing to introduction of extra stress into the lattice [61]. In another other reports, it was equally reported that the temperatureinduced conversion of titanates to the formation of anatase might as well caught up by the presence of existing metallic cations in the synthesis [62-65]. Remarkably, the superficial rate of intercalation of alkaline metal cations does not depend on the ion size, and the $d_{200}$ interplanar distance of the consequential structures which is also virtually indistinguishable for all alkaline metals $(0.88 \mathrm{~nm}$ for $\mathrm{H}$-form, $1.18 \mathrm{~nm}$ for alkaline forms) [53]. Thus, it is conceivable to augment additional functionality to layered titanate nanostructures by means of taking advantage of their ion-exchange characteristic features. Though ion exchange or nanoparticle deposition onto the surface are habitually termed 'doping' as reported [66], essentially, substitutional and interstitial doping of layered titanate materials are parallel to substituting either the framework $\mathrm{Ti}$ sites through
Figure 2 Overall of the process of transformation of raw $\mathrm{TiO}_{2}$ to nanotubular titanate.

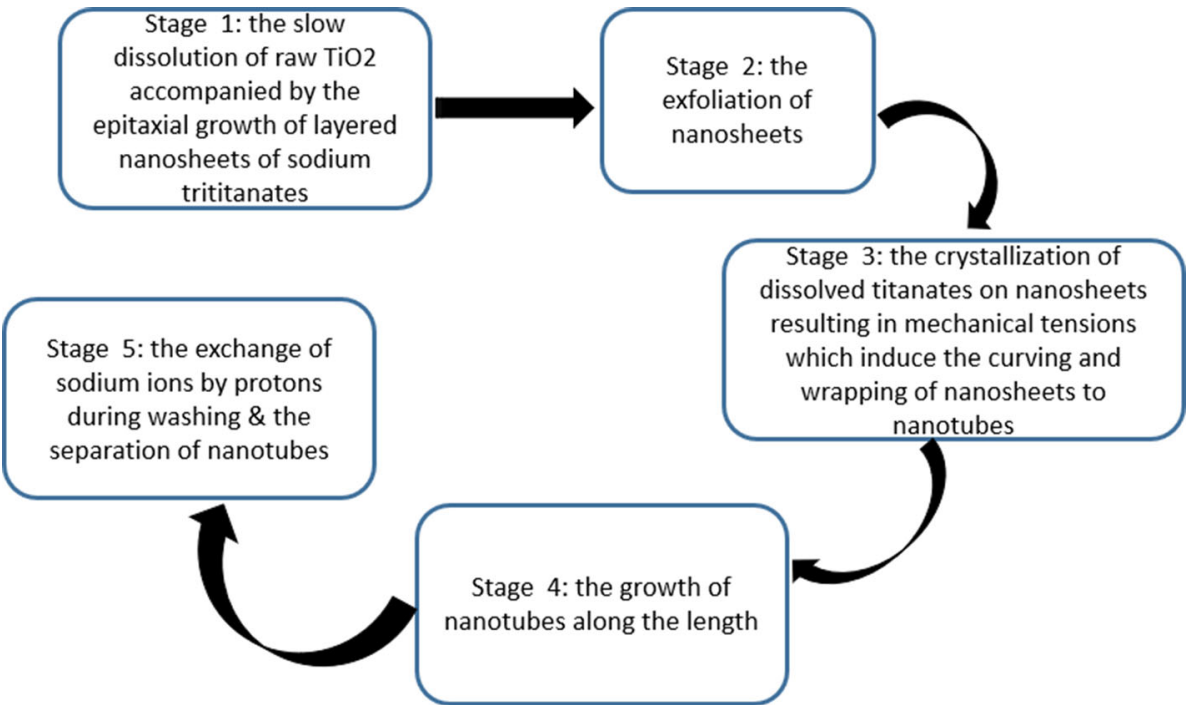


Figure 3 Exfoliating-rolling model of nanotube formation by a soft chemical method from layered $\mathrm{Na}_{2} \mathrm{Ti}_{3} \mathrm{O}_{7}$ particles [60].

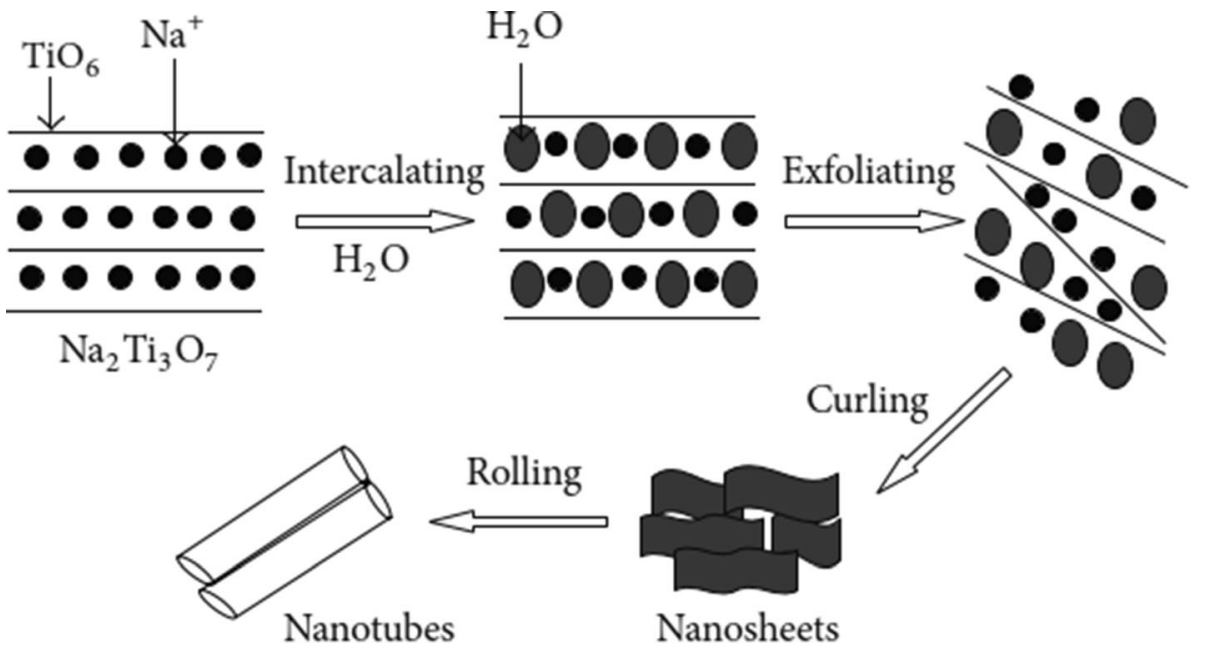

heteroatoms, or injecting extra atoms into the titanate framework, respectively. Evidence for framework Ti exchange was reported by Song et al. and co-worker for $\mathrm{Mn}, \mathrm{Cr}$ and $\mathrm{Cu}$ in trititanate nanotubes [67] and by $\mathrm{He}$ et al. and his colleagues for $\mathrm{Zr}$-doped $\mathrm{Na}_{2} \mathrm{Ti}_{4}$ $\mathrm{O}_{9}$ nanobelts [68].

\section{Exploitations of titanate nanotubes catalysts in chemical processes}

In the previous years, studies of the applications of titanate nanotubes in photocatalysis, catalysis, templates, batteries, sensors, and fuel cells have been carried out. Owing to the unique characteristic features of these titanate nanostructured materials, they have equally been employed in various chemical processes [69]. The various chemical processes where these titanate-derived materials were used as solid catalysts are reported below.

\section{Protonated titanate nanotubes as an efficient solid acid catalyst in Friedel-Crafts alkylation}

Recently, Kitano, M. et.al; described the use of protonated titanate nanotubes as an efficient solid acid catalyst in Friedel-Crafts alkylation and the production of 5-hydroxymethylfurfural (HMF) from glucose and fructose. The presence of both Bronsted and Lewis acid sites in titanate nanotubes was due to the interesting catalytic performance observed [13]. However, the authors argued that though the performance was indeed interesting but with an insufficient elucidation of the clear mechanistic relationship of the nanotube structure with the catalytic efficiency. To further unravel the mystery behind the catalytic activity of TNTs, they resorted to the synthesis of layered materials, nanosheets, and nanotubes titanate with diverse morphologies $\left(\mathrm{H}_{2} \mathrm{Ti}_{3} \mathrm{O}_{7}\right)$. These various synthesized morphologies were then used as heterogeneous solid acid catalysts for the Friedel-Crafts alkylation of toluene with benzyl chloride near room temperature to provide a concise structure-catalytic characteristic features relationship. Among these different morphologies used in the reaction, the titanate nanotube (with surface area $=$ $400 \mathrm{~m}^{2} \mathrm{~g}^{-1} ;$ BAS $=0.10 \mathrm{mmol} \mathrm{g}^{-1} ; 0.25 \mathrm{mmol} \mathrm{g}^{-1}$; yield of benzyl toluene (\%)=97.0@373 K,1 h, 92.0@ $300 \mathrm{~K}, 4 \mathrm{~h}$; TOF $=7.3 \mathrm{~min}^{-1}$ ) demonstrates excellent catalytic efficiency for the Friedel-Crafts alkylation of toluene with benzyl chloride in liquid phase, compared to the catalytic performance of layered titanates (with surface area $=16 \quad \mathrm{~m}^{2} \mathrm{~g}^{-1}$; BAS $=0.0 \mathrm{mmol} \mathrm{g}^{-1} ; 0.0 \mathrm{mmol} \mathrm{g}{ }^{-1}$; yield of benzyl toluene $(\%)=37.0 @ 373 \mathrm{~K}, 1 \mathrm{~h}, 0.0 @ 300 \mathrm{~K}, 4 \mathrm{~h}$; $\mathrm{TOF}=0.0 \mathrm{~min}^{-1}$ ) and that of nanosheets (with surface $\quad$ area $=75 \quad \mathrm{~m}^{2} \mathrm{~g}^{-1} ; \quad$ BAS $=0.03 \mathrm{mmol} \mathrm{g}^{-1}$; $0.12 \mathrm{mmol} \mathrm{g}^{-1}$; yield of benzyl toluene $(\%)=89.5$ $@ 373 \mathrm{~K}, 1 \mathrm{~h}, 7.6 @ 300 \mathrm{~K}, 4 \mathrm{~h}$; TOF $=0.7 \mathrm{~min}^{-1}$ ) that possess comparable crystal configurations to that of the titanate nanotubes synthesized from the same parent precursor [70]. The comprehensive relationship between surface area of the titanate materials employed in their study with the reported yield of benzyl toluene is given in Table 1, and it is evident that surface area significantly contribute to the yields of benzyl toluene. 
Table 1 Friedel-Crafts alkylation of toluene with benzyl chloride over various solid acid catalysts [70]

\begin{tabular}{|c|c|c|c|}
\hline \multirow[t]{2}{*}{ Catalyst } & \multirow{2}{*}{$\begin{array}{l}\text { Surface area } \\
\left(\mathrm{m}^{2} \mathrm{~g}^{-1}\right)\end{array}$} & \multicolumn{2}{|c|}{ Yield of benzyl toluene (\%) } \\
\hline & & $\begin{array}{l}373 \mathrm{~K}^{\mathrm{a}}, \\
1 \mathrm{~h}\end{array}$ & $\begin{array}{l}300 \mathrm{~K}^{\mathrm{b}}, \\
4 \mathrm{~h}\end{array}$ \\
\hline Titanate nanotubes & 400 & 97.0 & 92.0 \\
\hline $\mathrm{H}_{2} \mathrm{Ti}_{3} \mathrm{O}_{7}$ nanosheets & 75 & 89.5 & 7.6 \\
\hline $\mathrm{H}_{0.7} \mathrm{Ti}_{1.820 \cong 0.175} \mathrm{O}_{4} \cdot \mathrm{H}_{2} \mathrm{O}$ nanosheets & 106 & 92.5 & 7.6 \\
\hline Layered $\mathrm{H}_{2} \mathrm{Ti}_{3} \mathrm{O}_{7}$ & 5 & 0.0 & 0.0 \\
\hline Layered $\mathrm{H}_{0.7} \mathrm{Ti}_{1.825} \cong 0.175 \mathrm{O}_{4} \bullet \mathrm{H}_{2} \mathrm{O}$ & 16 & 37.0 & 0.0 \\
\hline $\mathrm{TiO}_{2}$ (anatase) & 300 & 94.0 & 0.0 \\
\hline
\end{tabular}

Reaction conditions: catalyst $(0.2 \mathrm{~g})$, toluene $(0.1 \mathrm{~mol})$, benzyl chloride $(0.02 \mathrm{~mol})$

${ }^{\text {a }}$ Product yield after the reaction at $373 \mathrm{~K}$ for $1 \mathrm{~h}$

${ }^{\mathrm{b}}$ Product yield after the reaction at $300 \mathrm{~K}$ for $4 \mathrm{~h}$
Under the employed reaction condition, $373 \mathrm{~K}$ temperature, both o-benzyl toluene and p-benzyl toluene were synthesized. However, it was not a smooth ride for the reacting species to access the interlayer space of layered titanates; it was resolved that the interlayer Lewis acid sites were absent for the reaction to take place [71] effectively. As for layered $\mathrm{H}_{2} \mathrm{Ti}_{3} \mathrm{O}_{7}$ catalyst, no catalytic performance was observed during the reaction, while layered $\mathrm{H}_{0.7}$ $\mathrm{Ti}_{1.825 \cong 0.175} \mathrm{O}_{4} \cdot \mathrm{H}_{2} \mathrm{O}$ demonstrated little catalytic activity owing to the vacant sites present in them, which might have acted as Lewis acid sites (LAS). However, the estimated volume of existing LAS on the layered titanates' surface, which was reportedly smaller than the volume of LAS on titanate materials, eventually led to their relative poorer catalytic performance, while at $300 \mathrm{~K}$, the parent precursor (i.e., $\mathrm{TiO}_{2}$ ) and the layered titanates which possess Lewis acid sites alone demonstrated insignificant catalytic performance. It was also reported that the presence of both Lewis and Brønsted acid sites in titanate nanosheets and nanotubes facilitated alkylation reaction owing to accessibility of the reacting molecules to both LAS and BAS. They concluded that Brønsted acid sites facilitate alkylation reaction on the existing Lewis acid sites at room temperature. To confirm this hypothesis, the authors employed 2,6lutidine via alkylation reaction which selectively interact with only Brønsted acid sites. At the same time, there was no reaction with Lewis acid sites due to steric hindrance [72]. Titanate nanotubes demonstrated a surface area more than nanosheet in four times even as they were both synthesized from the same parent precursor, the bigger surface area exhibited could be conclude to be one of the reasons for the fascinating catalytic performance, when compared to those of nanosheet derived materials.

Nevertheless, the outstanding catalytic activity of titanate nanotubes cannot be elucidated solely by their surface area since titanate nanotubes have a TOF value that is tenfold higher than titanate nanosheets. They further conduct more characterizations to get details in-depth of the materials. Based on Raman spectroscopy, titanate nanotubes (TNTs) displayed a distorted structure, unlike the titanate nanosheets, resulting from bending of the $\mathrm{TiO}_{6}$ octahedral layers of the NTs. FT-IR study shows that TNTs are stronger Brønsted acid than titanate nanosheets, and the acidity of the nanotubes' internal and external surfaces is nearly identical. This shows that lattice alteration owing to the scrolling of titanate nanosheets might have led to active BAS, facilitating carbocation reaction, which takes place on the LAS with $\mathrm{HCl}$ production as a by-product. They concluded that the synergetic effect between LAS and BAS led to efficient alkylation on the titanate nanotubes. Besides, titanate nanotubes also possess mesoporous structures that could have provided easy access for the reactants to the exposure of acid sites within the nanotubes [70].

The hydroxyalkylation/alkylation (HAA) of 2-methyl furan (2-MF) and n-butanal over protonated titanate nanotubes (HTNT)

In another report, protonated titanate nanotube (PTNT) was also employed as efficient solid acid catalysts to synthesize biofuel intermediates. The hydroxyalkylation/alkylation (HAA) of 2-methyl furan (2-MF) and n-butanal, the two platform 
molecules obtained from renewable feedstocks, were investigated over PTNT (Fig. 4). The catalyst exhibit superior catalytic performance compared with the other commonly used inorganic solid acid catalysts (H-ZSM-5, H-MOR, ZrP, H- $\beta, \mathrm{SO}_{4}{ }^{2-} / \mathrm{Al}_{2} \mathrm{O}_{3}, \mathrm{SO}_{4}{ }^{2-}$ / $\mathrm{ZrO}_{2}$ ) employed in the study. It was shown that PTNT possesses higher catalytic activity and efficiency, which led to the attractive high yield of hydroxyalkylation/alkylation product of about $77 \%$ contents. To check the universality of this material, reactions of 2-methyl furan were also performed between other bio-derived carbonyl compounds (Butanal, Furfural, Acetone, and Mesityl Oxide) via HAA (or alkylation), and PTNT was also confirmed effective for the alkylation or hydroxyalkylation reaction [73].

However, among all the carbonyl compounds investigated, n-butanal demonstrated attractive reactivity. The interesting reactivity of n-butanal observed was attributed to the higher activity of aldehyde (or by the steric hindrance of the furan group) than ketone [74]. Based on characterization analysis, they attributed the performance of PTNT to the hydrothermal treatment of commercial $\mathrm{TiO}_{2} \mathrm{P} 25$ (with Surface area $=65 \mathrm{~m}^{2} \mathrm{~g}^{-1}$; Average pore size $=$ $18.3 \mathrm{~nm}$; Pore volume $=0.3 \mathrm{~mL} \mathrm{~g}^{-1}$; Amount of acid site $=0.2 \mathrm{mmol} \mathrm{g}^{-1}$ ) with $\mathrm{NaOH}$ solution and subsequent acidification which resulted to impressive increases in the surface area of PTNT and the

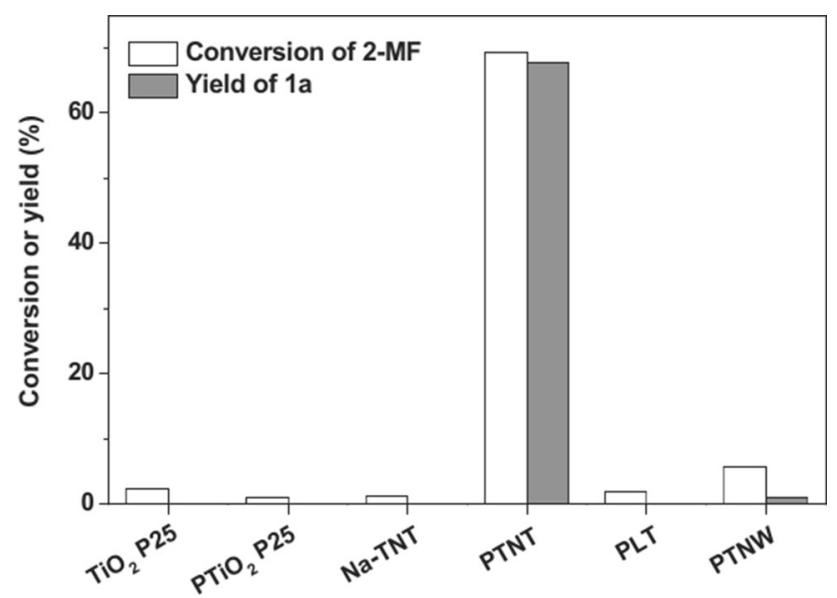

Figure 4 Over various titania catalysts, the 1a (gray bar) yields and conversions of 2-MF (white bar) were calculated. The experimental parameters employed are as follows: $3.28 \mathrm{~g}, 323 \mathrm{~K}$, $4 \mathrm{~h}$ (40 mmol) 2.MF, $1.44 \mathrm{~g}$ n-butanal $(20 \mathrm{mmol}), 0.15 \mathrm{~g}$ catalyst,

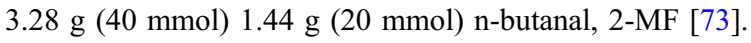

adequate sufficient acid sites present on the surface of PTNT (with Surface area $=350 \mathrm{~m}^{2} \mathrm{~g}^{-1}$; Average pore size $=7.5 \mathrm{~nm}$; Pore volume $=0.79 \mathrm{~mL} \mathrm{~g}^{-1}$; Amount of acid site $=1.1 \mathrm{mmol} \mathrm{g}^{-1}$ ). Before hydrothermal treatment, the surface area of commercially obtained $\mathrm{TiO}_{2} \mathrm{P} 25$ was $65 \mathrm{~m}^{2} \mathrm{~g}^{-1}$; however, after the reacting species were subjected to hydrothermal treatment, the ion-exchange process and subsequent washing responsible for as-prepared PTNT with an impressive surface area of $350 \mathrm{~m}^{2} \mathrm{~g}^{-1}$.

The authors equally attributed these treatments to the formation of strong acid sites and Brönsted acid sites present on the surface of PTNT catalyst, which eventually led to the interesting catalytic performance reported for the synthesis of biofuel intermediates which were later used in the manufacture of renewable diesel and jet fuels over zeolite-loaded $\mathrm{Ni}$ catalysts via hydrodeoxygenation process [73]

As we already know, reusability is one of the key factors determining the industrial application and acceptability of solid acid catalysts. The authors conducted a stability test and reported three subsequent runs for the PTNT, where a slight deactivation was observed after the third run. To investigate the reason for the deactivation, the authors investigated the presence of water on the fresh PTNT. They found out that water does not affect the catalyst. Further characterization of fresh PTNT and used PTNT (after three consecutive runs) were carried out where it was clearly shown that the specific BET surface area, average pore size, pore volume, and amount of acid sites decreased from 350 to $271 \mathrm{~m}^{2} \mathrm{~g}^{-1}, 7.5$ to $4.2 \mathrm{~nm}$, 0.79 to $0.57 \mathrm{~mL} \mathrm{~g}^{-1}$ and 1.1 to $1.0 \mathrm{mmol} \mathrm{g}^{-1}$, respectively [73].

To justify the reason for deactivation in their study, they attributed it to the formation of polymeric molecules that might have impeded HAA reactions of 2-MF compared to what they previously reported over Amberlyst resins [74, 75]. They ascertained that polymeric molecules might be responsible for the blockage of the pore and also hinders easy access to the existing acid sites existing on the protonated titanate nanotubes' surface. The authors equally investigated the effect of $\mathrm{TiO}_{2}$ morphology; from Fig. 4, the catalytic activity of the PLT and the PTNW showed that these morphologies are ineffective for the HAA reaction of 2-MF with n-butanal. In a nutshell, three cogent points responsible for the impressive catalytic activity of protonated titanate nanotubes for hydroxyl alkylation/alkylation of 
2-MF and n-butanal were identified; (a) Higher specific surface area (b) Higher acidity: the acid strength of catalysts has a big impact on the HAA of 2-MF. As a result, a strong acid is more active than a weak acid in the 2-MF HAA reactions [74, 75]. (c) Brönsted acid sites: this is also responsible for the high reactivity observed for the hydroxyl alkylation/ alkylation reactions of 2-MF and n-butanal [73].

\section{One-dimensional (1D) protonated titanate nanostructures as heterogeneous solid acid catalysts via an aldol condensation reaction}

Sluban et al. also used aldol condensation reaction to use 1D HTNT nanostructures as heterogeneous solid acid catalysts. They investigated the catalytic activity of two separate synthesized protonated titanate nanostructure morphologies (namely nanotubes and nanoribbons) from commercial $\mathrm{TiO}_{2}$ using bioderived platform molecules benzaldehyde and cyclohexanone. Protonated titanate nanotubes were found to have superior catalytic efficiency for aldol condensation of benzaldehyde and cyclohexanone compared to nanoribbons. The other authors attributed the output of protonated titanate nanotubes possessing LAS and BAS with strong acid sites. Simultaneously, nanoribbons also possess both LAS and BAS, but the acid sites were stated to be medium strength. After five consecutive runs of stability tests, no noticeable deactivation of protonated titanate nanotubes was observed. The catalytic activity of HTNT was verified in a large-scale experiment [76], which was the study's selling point. With this in mind, these materials are anticipated to be beneficial to relevant industrial sectors-chemicals and fuel-related aspects. Furthermore, for these novel materials, no activation is required before reaction activity.

The reaction mechanism for catalytic efficiency of titanate nanotubes was proposed for aldol condensation of benzaldehyde and cyclohexanone (see scheme 1) in agreement with the presence of strong acid sites on the surface of titanate nanotubes [76]. To get clear details of the mechanistic study of the reaction, the authors only showed the condensation on one side of cyclohexanone. They believed that the reaction began with the successful activation of reagents and reacting species due to hydrogen transfer from the HTNTs' bridging -OH groups.

From previous reports, it has been reported that in protonated titanates $\left(\mathrm{H}_{2} \mathrm{Ti}_{3} \mathrm{O}_{7}\right)$, the two major types of hydroxyl groups always present on their surface (namely terminal and bridging -OH groups), where the latter ones have been identified with significant higher acid strength [70, 77-79]. Therefore, tautomerism is inevitable for the conversion of the ketone to enole, which is responsible for the attacks of an activated electrophile on benzaldehyde. This then leads to the formation of aldol product accompanied by dehydration which subsequently accounts for the desorption of the product from the surface of the novel protonated titanate nanotubes (HTNT) [76].

\section{Depolymerization of PET (virgin and post- consumer) granulometry Over NaTNT and HTNT solid catalysts}

In their recent study, G. R. Lima et al. synthesized NaTNT and HTNT for depolymerization of PET bottles which their accumulation can cause environmental discomfort [80]. The disposal of these PET bottles is a major problem owing to strong tolerance to biological degradation and environmental conditions. Doing nothing to these wastes could lead to various health challenges. In their recent study, depolymerization was considered as the best option to produce value-added products from supposed wastes using NaTNT/HTNT as a solid catalyst. The titanate materials were synthesized via the hydrothermal technique. With the option of chemical recycle via glycolysis as a productive bio-based economy. The objectives of their work were carried out in two major steps. They first investigated the influence of PET (virgin and post-consumer) granulometry, EG: PET ratio $(\mathrm{w} / \mathrm{w})$, and amount of NaTNT (mol\%), likewise reaction time was checked too, while in the second step, their objective was based on the comparative investigation of catalytic performance of both sodium NaTNT and HTNT synthesized from the same parent precursors (commercial $\mathrm{TiO}_{2}$ ) as effective solid catalysts for depolymerization of PET via glycolysis.

PET was catalyzed using hydrothermally obtained sodium/protonated titanate nanotubes that resulted in bis(hydroxyethyl)terephthalate (BHET), a valueadded monomer. The best relationship yield/amount of ethylene glycol used in the EG/PET ratios was 4:1 percent. As a result, this research demonstrates that NaTNT and HTNT are effective catalysts for the depolymerization of PET through glycolysis with high yields. However, from this report, HTNT acts 
Scheme 1 According to a proposed mechanism, long titanate nanotubes catalyzed aldol condensation between benzaldehyde and cyclohexanone [76].

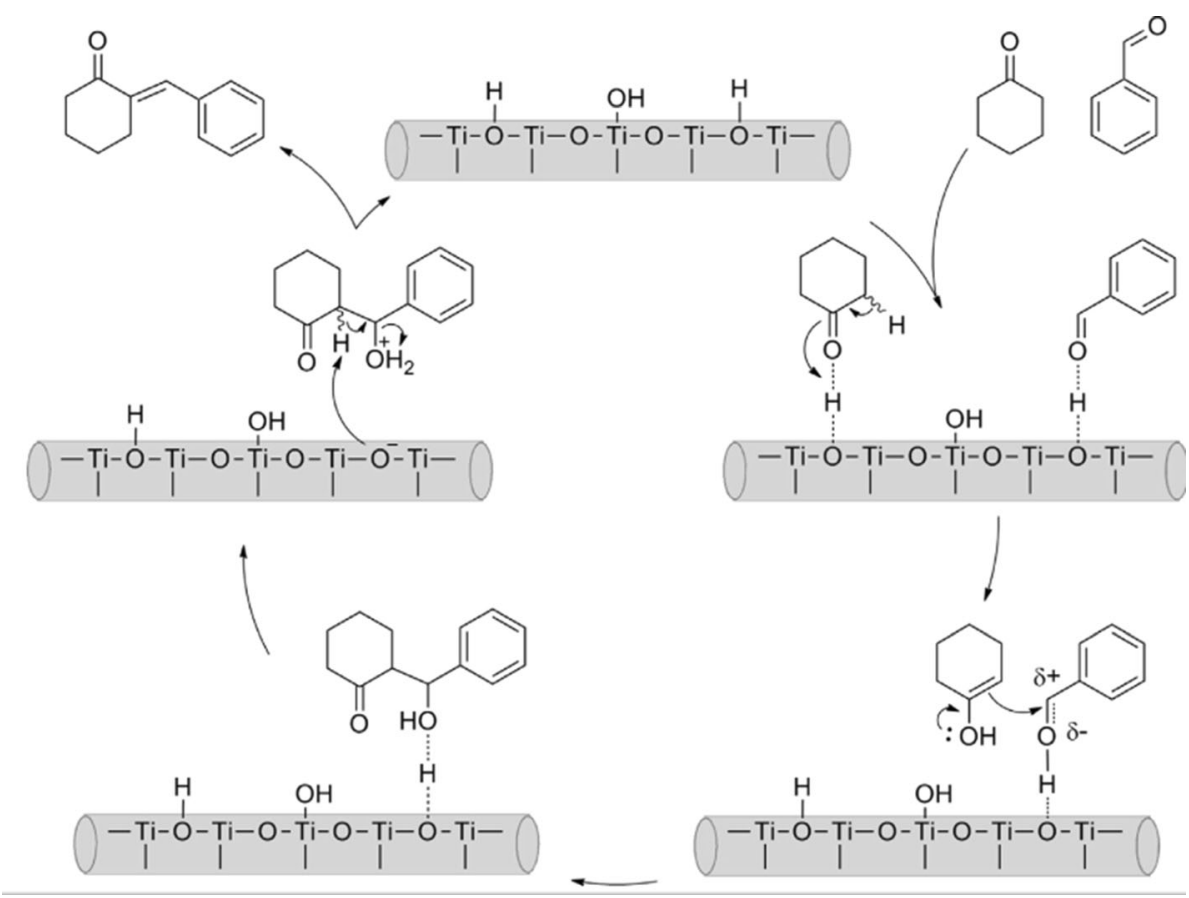

more promising solid catalyst than NaTNT for PET glycolysis with the highest yield of $88 \%$, while $84 \%$ yield was obtained when NaTNT was used at the same reaction time of $3 \mathrm{~h}$ depolymerization of virgin PET. TPD's characterization study revealed that protonated titanate nanotubes were more effective than sodium titanate nanotubes due to a higher concentration of Brönsted and Lewis acid sites. Therefore, the study was considered as a novel as the highest PET yields (i.e., 88\% PET yield by HTNT and $84 \%$ PET yield when NaTNT was applied as a solid catalyst) as against previous study with other solid catalysts where the maximum PET yield ranges between 70 and $80 \%$ BHET [81].

The tubular morphology of NaTNT and HTNT used for depolymerization are identical, with a difference in external diameter of $8.8 \pm 0.8 \mathrm{~nm}$ for NaTNTs (Fig. 5). In contrast, HTNTs were reported to be $10.4 \pm 0.8 \mathrm{~nm}$ determined by Image J software. Definite tubular morphology was visible in NaTNT with internal walls compared to the rough surface and a lower crystallinity as reported in the previous studies [70, 71].
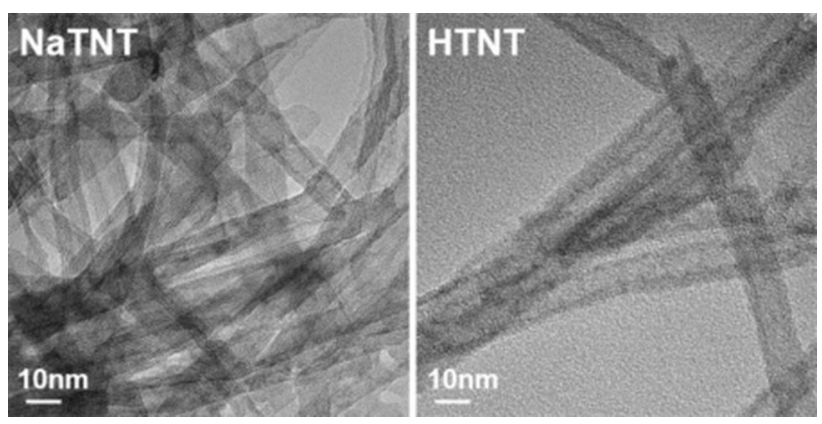

Figure 5 TEM analysis of NaTNT and HTNT catalysts. Both synthesized titanate materials exhibited similar morphology; however, their external diameter calculated using Image J software is different $(8.8 \pm 0.8 \mathrm{~nm}$ to NaTNT and $10.4 \pm 0.8 \mathrm{~nm}$ to HTNT) respectively [80].

\section{Synthesis of 5-(hydroxymethyl)furfural from glucose over low temperature derived hydrogen titanate nanotubes}

In their work, Misaki and co-workers, hydrogen titanate $\left(\mathrm{H}_{2} \mathrm{Ti}_{3} \mathrm{O}_{7}\right)$ nanotubes were synthesized at low temperature for the first time using a new facile technique where amorphous $\mathrm{TiO}_{2}$ nanoparticles with the large surface area were employed as precursors for the preparation of the catalysts at room temperature. $\mathrm{Na}^{+}$was introduced into the amorphous $\mathrm{TiO}_{2}$ $\left(\mathrm{a}-\mathrm{TiO}_{2}\right)$ nanoparticles at ambient temperature, followed by an ion-exchange process to synthesize 
$\mathrm{H}_{2} \mathrm{Ti}_{3} \mathrm{O}_{7}$ nanotubes [82]. The amorphous $\mathrm{TiO}_{2}$ (a$\mathrm{TiO}_{2}$ ) used in their study was synthesized using $1.4 \mathrm{~g}$ of titanium tetraisopropoxide (TTIP) which was mixed with $30 \mathrm{~g}$ of organic solvent (1-butanol $(\mathrm{BtOH})$, diethyl ether (Et2O), hexane (Hex), ethanol $(\mathrm{EtOH})$, acetone (Ace), isopropanol (IPA), and tetrahydrofuran (THF)). The mixture was subjected to stirring at room temperature one hour reaction time. Afterward $1.6 \mathrm{~mL}$ of water was measured and added in order to facilitate hydrolysis reaction. At the end, $\mathrm{TiO} 2$ powder was obtained via centrifugation and further dried at $363 \mathrm{~K}$ reaction temperature [83]. Remarkably, a high surface area of $735 \mathrm{~m}^{2} / \mathrm{g}$ (the highest so far) was reported for the $\mathrm{H}_{2} \mathrm{Ti}_{3} \mathrm{O}_{7}$ nanotubes produced at ambient temperature. (Amorphous $\mathrm{TiO}_{2}$ was reacted with $10 \mathrm{M} \mathrm{NaOH}$ aqueous solution for a reaction time of $48 \mathrm{~h}$. The precipitate formed (i.e., $\mathrm{Na}_{2} \mathrm{Ti}_{3} \mathrm{O}_{7}$ ) was washed with a $0.1 \mathrm{M} \mathrm{HCl}$ solution until it reached a $\mathrm{pH}$ value of 1 via ion-exchange activity between sodium ion and hydrogen ion). For comparison, they also synthesized $\mathrm{H}_{2} \mathrm{Ti}_{3} \mathrm{O}_{7}$ via hydrothermal protocol using $\mathrm{P} 25 \mathrm{TiO}_{2}$ as a precursor. However, the surface area of $408 \mathrm{~m}^{2} / \mathrm{g}$ obtained was lower than the materials synthesized at room temperature; both catalysts were used to transform bio-derived glucose into 5-(hydroxymethyl) furfural. For clarification, the $\mathrm{H}_{2} \mathrm{Ti}_{3} \mathrm{O}_{7}$ samples produced at ambient temperature from a- $\mathrm{TiO}_{2}$ and by hydrothermal treatment from $\mathrm{P} 25-\mathrm{TiO}_{2}$ were tagged HTO-RT and HTO-HT, respectively [82].

5-hydroxymethylfurfural (HMF) stands out in the biorefinery roadmap as a connection between biomass raw materials and alternative fuels, chemicals, and materials that could replace petroleum-derived products [84]. TEM images are shown Fig. 6. To have nanotubes synthesized, both peeling and scrolling processes are required. $\mathrm{Na}_{2} \mathrm{Ti}_{3} \mathrm{O}_{7}$ nanosheets are formed on $\mathrm{TiO}_{2}$ particles first, and then the nanosheets delaminate from $\mathrm{TiO}_{2}$ particles in $\mathrm{NaOH}$ solution. In the final stage, the nanosheets obtained then rolled up to form nanotubes materials as the ion-exchange process between $\mathrm{Na}^{+}$ions and $\mathrm{H}^{+}$ions was conducted. The details of HMF yield from glucose or fructose over the solid catalysts used was quantified (Fig. 7). It was affirmed that the isomerization of glucose into fructose under base site or Lewis acid site was accompanied by the transformation which occurred via dehydration of fructose to HMF with a strong influence of Brønsted acid site. From the results, the HTO samples (i.e., HTO-RT and HTO-
HT) demonstrated an interesting high yield of HMF from glucose, indicating that the $\mathrm{H}_{2} \mathrm{Ti}_{3} \mathrm{O}_{7}$ nanotube possesses both LAS and BAS compared with $\mathrm{HCl}$ and Amberlyst- 15 that only have BAS. Owing to the absence of LAS in $\mathrm{HCl}$ and Amberlyst- 15 materials, the HMF yield obtained from glucose was lower than HTO samples. Interestingly, HTO-RT also demonstrated a higher HMF yield from fructose than HTOHT. It was concluded that the higher yield obtained for HMF over HTO-RT catalyst could be credited to possession of more Brønsted acid sites on the surface of nanotube than HTO-HT regarding the high surface area reported for HTO-RT [82].

\section{Synthesis of jet fuel precursors}

over protonated titanate nanotube (PTNT) solid acid catalyst

In another study conducted on the synthesis of biofuel precursor's biomass-based platform, molecules were used. Methyl benzaldehyde (2-and-4 methyl benzaldehyde) and acetone obtainable from lignocellulose were transformed to biofuels precursors over solid acid protonated titanate nanotube (PTNT) through aldol condensation [8]. The authors first manufactured series of protonated titanate nanotubes from commercial P25 $\mathrm{TiO}_{2}$ and aqueous sodium hydroxide via a hydrothermal method, as earlier reported by Kasuga et al. [13]. They further produced the protonated layered titanate (PLT) via solid-state reaction protocol. $\mathrm{TiO}_{2} \mathrm{P} 25$ and $\mathrm{Na}_{2} \mathrm{CO}_{3}$ were homogeneously mixed at a molar ratio of 3.0: 1.1. The combination was put in a muffle oven and subjected to calcination at $1073 \mathrm{~K}$ for $18 \mathrm{~h}$. Once crushed, the mixture was re-annealed for additional $20 \mathrm{~h}$ to obtain the layered sodium titanate $(\mathrm{NaLT})$ at another $1073 \mathrm{~K}$. The NaLT was ion-exchanged with $1 \mathrm{~mol} \mathrm{~L}^{-1}$ $\mathrm{HCl}$ aqueous solution (they keep renewing the $\mathrm{HCl}$ aqueous solution daily). To make PLT, the solid material obtained through ion exchange was filtered, washed with deionized water, and dried for $12 \mathrm{~h}$ at $333 \mathrm{~K} \mathrm{[13],} \mathrm{while} \mathrm{protonated} \mathrm{titanate} \mathrm{nanowire}$ (PTNW) was also prepared via the hydrothermal method with modification of time seven days' reaction time [57].

These three different titanate nanostructured materials, in addition to $\mathrm{P} 25 \mathrm{TiO}_{2}$, were employed for aldol condensation of methyl benzaldehyde and acetone (Fig. 8). Among these titanate nanostructured materials employed in their study, PTNT was 


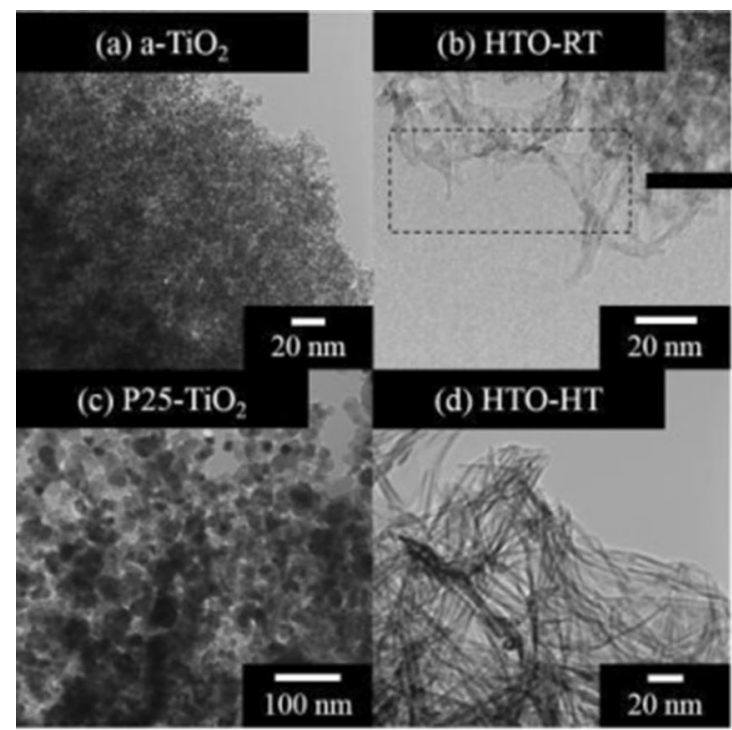

Figure 6 TEM images of raw materials and HTO samples: a commercially available $\mathrm{P} 25-\mathrm{TiO}_{2}$, b $\mathrm{H}_{2} \mathrm{Ti}_{3} \mathrm{O}_{7}$ nanotubes synthesized by conventional hydrothermal method from P25-

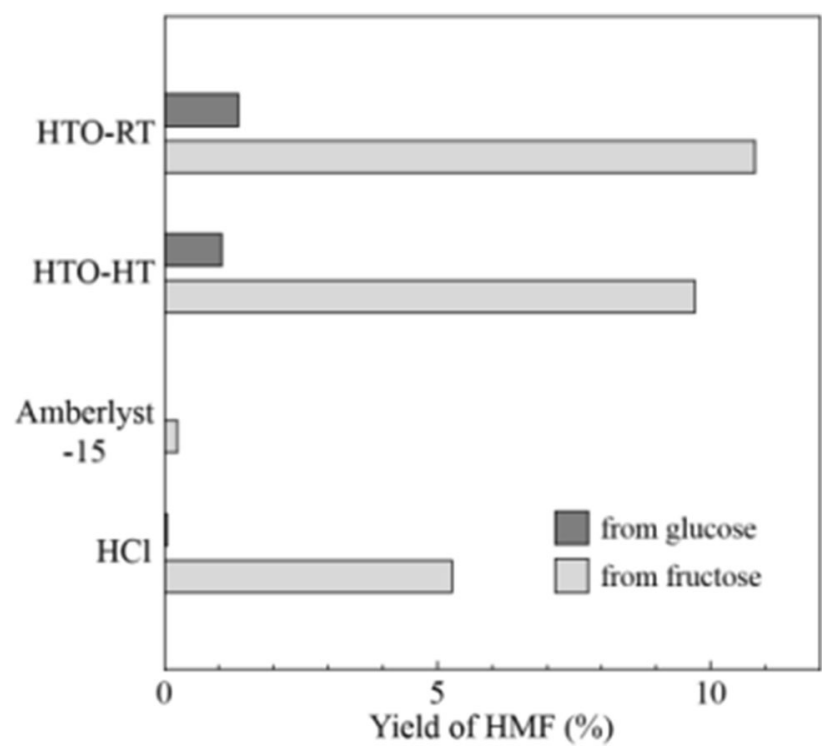

Figure 7 HMF yield from glucose or fructose under the catalysts. HMF yield. Adapted with permission from ref. [82].

reported to be more efficient in aldol condensation of 2-methyl benzaldehyde and acetone compared to the catalytic performance of PTNW and PLT. The performance of both PTNW and PLT was still less than the $\mathrm{TiO}_{2}$ P25 precursor. They attributed the catalytic performance to the large surface area of PTNT $\left(\mathrm{S}_{\mathrm{BET}}=529 \mathrm{~m}^{2} \mathrm{~g}^{-1}\right) ; \mathrm{S}_{\mathrm{BET}}$ of $\mathrm{TiO}_{2} \mathrm{P} 25$ considerably increased from 72 to $529 \mathrm{~m}^{2} \mathrm{~g}^{-1}$ after hydrothermal treatment. This was equally attributed to the porous

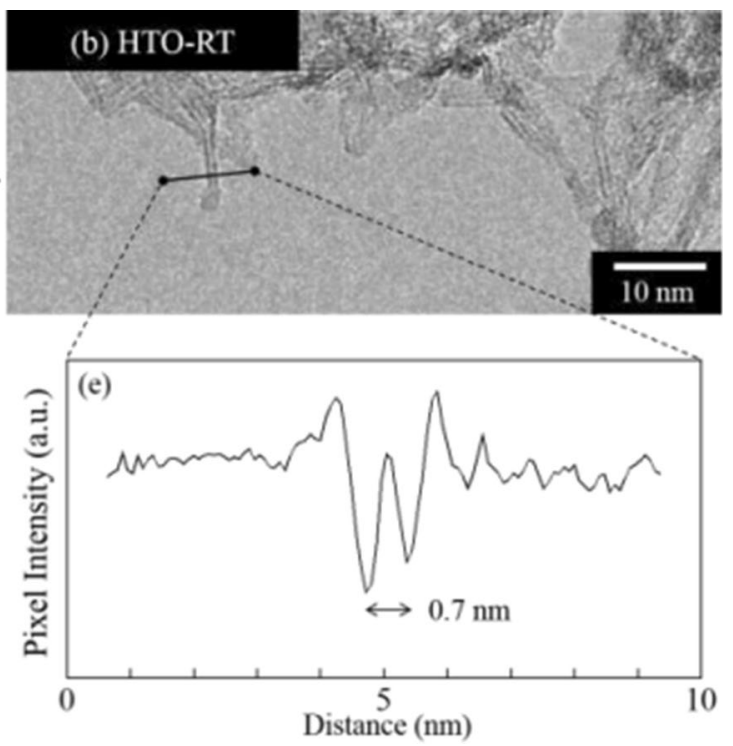

$\mathrm{TiO}_{2}$, c amorphous $\mathrm{TiO}_{2}$, and $\mathbf{d ~} \mathrm{H}_{2} \mathrm{Ti}_{3} \mathrm{O}_{7}$ nanotubes synthesized at room temperature from amorphous $\mathrm{TiO}_{2}$. e 1D profile of HTO-RTA adapted with permission from ref [82].

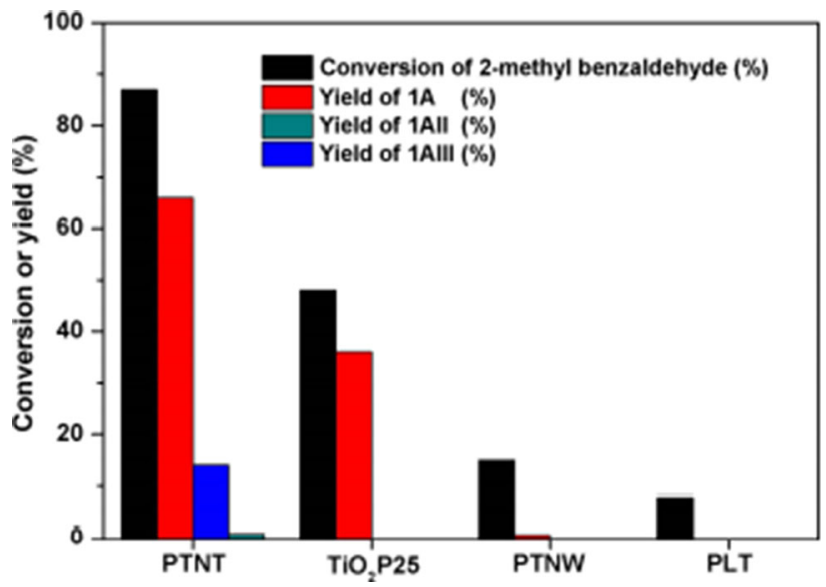

Figure 8 Conversions of 2-methyl benzaldehyde and the yields of different products by using titanates. $10 \mathrm{~mL}$ acetone, $5 \mathrm{mmol}$ 2-methyl benzaldehyde, $0.15 \mathrm{~g}$ titanate catalyst, $343 \mathrm{~K}$ for $8 \mathrm{~h}$ [8].

nanotube structure of protonate titanate nanotubes, while the $S_{\text {BET }}$ of PTNW and PLT are $40 \mathrm{~m}^{2} \mathrm{~g}^{-1}$ and 4 $\mathrm{m}^{2} \mathrm{~g}^{-1}$, respectively [8].

These are inferior to their parent precursor $\mathrm{TiO}_{2}$ P25 $\left(72 \mathrm{~m}^{2} \mathrm{~g}^{-1}\right)$. Furthermore, surface Brönsted acid sites' existence was also well-thought-out as one of the major reasons PTNT demonstrated superior catalytic performance. The high yield of $\sim 76 \%$ of jet fuel originators was obtained in trivial reaction settings. One more fascinating part of their work is the stability of the materials at a lower conversion of $0.5 \mathrm{~h}$ reaction time with five consecutive runs. No 
major decrease in catalytic activity was noticed after five repeated use (Fig. 9) [8]. In summary, the good activity of PTNT was ascribed to its unique morphology, higher surface area, higher acid site amount, and acid strength.

\section{Titanate nanotubes-bonded organosulfonic acid $\left(\mathrm{TNT}-\mathrm{SO}_{3} \mathrm{H}\right)$ as solid catalyst for esterification LA with n-butyl alcohol}

Commonly used conventional acid catalysts such as $\mathrm{H}_{2} \mathrm{SO}_{4}$ and p-toluene-sulfonic acid have been reported to produce n-butyl levulinate through esterification reaction levulinic acid (LA) with n-butyl alcohol [85]. Nevertheless, it is no longer a new story that utilization of mineral acid catalysts come with drawbacks such as the generation of wastes, severe corrosion of reacting vessels, and other safety issues that render these set of catalysts unsuitable and unsustainable. Therefore, it is highly recommended that chemists embark on developing recyclable heterogamous catalysts [8]. The development of sustainable derived solid acid catalysts for the production of bio-derived compounds is receiving attention to bridge the existing research gap [86, 87]. To fill in the research gap, Shuolin Zhou and colleagues synthesized titanate nanotubes-bonded organosulfonic acid by chemical grafting-oxidation technique with (3-mercaptopropyl) trimethoxysilane as starting material and $\mathrm{TiO}_{2}$ nanotubes as a template (see Scheme 2) and subsequently adopted as solid acid catalysts in the esterification reaction of levulinic acid

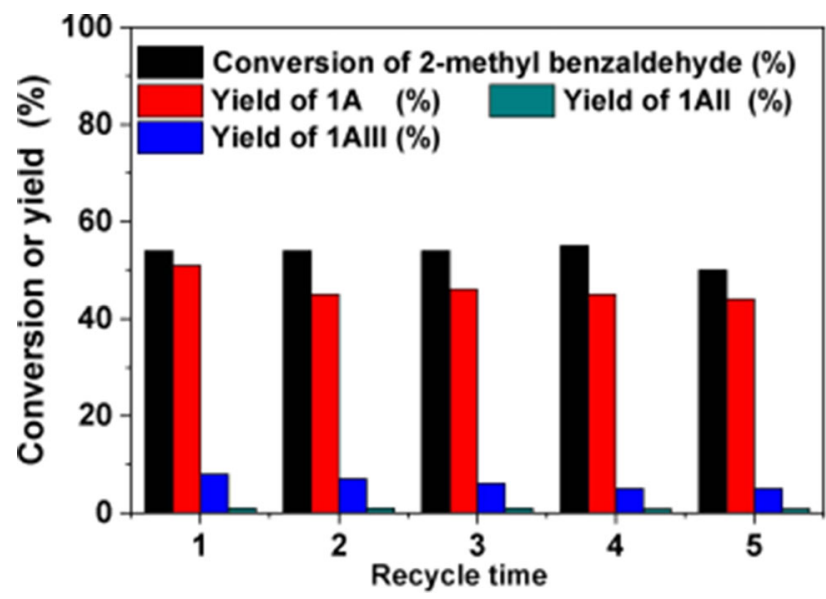

Figure 9 Over the PTNT catalyst, conversions of 2-methyl benzaldehyde and yields of different products were observed. Conditions of reaction: $353 \mathrm{~K}, 0.5 \mathrm{~h}, 10 \mathrm{~mL}$ acetone, $5 \mathrm{mmol}$ 2-methyl benzaldehyde, $0.15 \mathrm{~g}$ PTNT catalyst [8]. with n-butyl alcohol [88]. They prepared the catalysts according to the method reported by Kasuga and his co-workers [13].

To synthesize TNTs- $\mathrm{SO}_{3} \mathrm{H}, 4 \mathrm{~mL}$ (3-mercaptopropyl) trimethoxysilane was dropped into a threenecked round-bottom holding $1.0 \mathrm{~g}$ of TNTs and $15 \mathrm{~mL}$ of dry toluene, and the content was refluxed for $24 \mathrm{~h}$ under with influence of stirring. The product was then subjected to filtration and subsequently washed with acetone. The powder synthesized was also oxidized with $10 \mathrm{wt} \% \mathrm{H}_{2} \mathrm{O}_{2}$ in methanol $(10 \mathrm{~mL})$ at $298 \mathrm{~K}$ for a day, with an acidification process of $1 \mathrm{~mol} \mathrm{~L}^{-1} \mathrm{H}_{2} \mathrm{SO}_{4}$ for the protonation process. The prepared contents were filtered and then washed with $\mathrm{H}_{2} \mathrm{O}$ and acetone to produce TNTs $-\mathrm{SO}_{3} \mathrm{H}$ solid acid catalyst. The catalytic efficiencies of all the materials employed in the study (i.e., TNPs, TNTs, and TNTs- $\mathrm{SO}_{3} \mathrm{H}$ ) were examined for LA transformation, and the results are given in Table 1 . The author conducted a blank experiment in the absence of catalyst; the conversion obtained for LA was quantified to be $6.3 \%$ (see Table 2, entry 1 ).

The synthesized TNTs- $\mathrm{SO}_{3} \mathrm{H}$ catalyst exhibited interesting catalytic performance for synthesizing alkyl levulinate from biomass-derived platform molecules. The transformation of LA and target product (BL) were produced under comparatively trivial conditions.

With the aid of GC-MS, two major yields (pseudon-butyl levulinate (pseudo-BL) and n-butyl levulinate (BL)) were identified and quantified. The catalyst converted levulinic acid to n-butyl levulinate with an efficiency of 86.8 percent and a selectivity of 99.7 percent. The stability test was also investigated on TNTs $-\mathrm{SO}_{3} \mathrm{H}$ to demonstrate high stability even after seven consecutive use, advantageous for industrial applications. With this in mind, it was determined that the catalyst could be recycled without significant performance loss. The express accessibility of the $\mathrm{SO}_{3} \mathrm{H}$ sites in catalyst enhanced the high yield obtained at entry 7 (Table 2); the reaction smoothly took place on this account. Furthermore, the wide dispersion of the catalyst in reaction media also contributed to the performance. The pore openings of TNTs- $\mathrm{SO}_{3} \mathrm{H}$ are expected to enable fast diffusion of such molecules within the pore system to active sites of the TNTs- $\mathrm{SO}_{3} \mathrm{H}$ due to the relative proportions of LA and pseudo-BL.

Furthermore, the selectivity of BL on the reused catalyst was nearly identical to that on the new 
Scheme 2 Schematic strategy for the synthesis of TNTs$\mathrm{SO}_{3} \mathrm{H}$ solid acid catalysts [88].
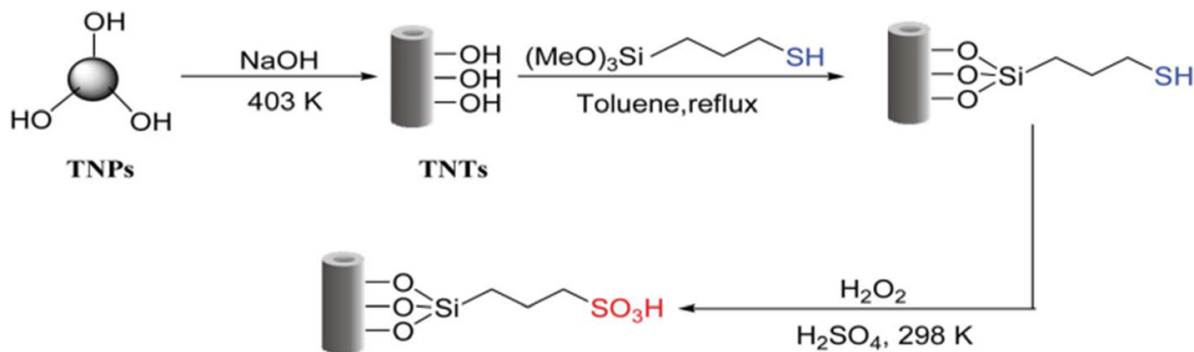

TNTs-SO ${ }_{3} \mathrm{H}$
Table 2 Catalytic activity over different catalytic materials [88]

\begin{tabular}{llllll}
\hline Entry & Catalyst & Time (h) & LA Conversion (\%) & \multicolumn{2}{c}{ Selectivity (\%) } \\
\cline { 5 - 6 } & & & BL & Pseudo-BL \\
\hline 1 & - & 2 & 6.3 & 36.8 & 63.2 \\
2 & TNPs & 2 & 11.0 & 44.6 & 55.4 \\
3 & TNPs & 2 & 15.4 & 64.9 & 35.1 \\
4 & TNPs & 6 & 25.5 & 80.4 & 19.6 \\
5 & TNTs- $\mathrm{SO}_{3} \mathrm{H}$ & 2 & 27.9 & 81.5 & 18.5 \\
6 & $\mathrm{TNTs}-\mathrm{SO}_{3} \mathrm{H}$ & 2 & 37.5 & 84.4 & 15.6 \\
7 & $\mathrm{TNTs}-\mathrm{SO}_{3} \mathrm{H}$ & 4 & 48.2 & 97.0 & 3.0 \\
\hline
\end{tabular}

${ }^{\text {a }}$ Experimental condition: $1 \mathrm{mmol}$ of LA, $5 \mathrm{mmol}$ of n-butanol, $5 \mathrm{wt} \%$ catalyst loading, $383 \mathrm{~K}$ catalyst. Despite a small activity decay, which may be attributed to the decline of the catalyst's mass after many recovering loops, LA conversion only drops from $86.8 \%$ to 81.20 percent after seven cycles. The existence of strong acid sites was credited with catalytic efficiency. Because of their environmentally friendly characteristics, the authors concluded that TNTs $-\mathrm{SO}_{3} \mathrm{H}$ nanocatalysts are effective and sustainable for the esterification of bio-derived synthesis and related applications [88].

\section{Application of one-dimensional sodium titanate nanotubes (STNTs) Solid catalyst for sustainable synthesis of biodiesel via esterification.}

One of the pressing issues faced by the entire world now is the energy and fuel crisis since most of the current fuels and energy consumption recently are non-renewable with environmental threats. Therefore, there is a need to source renewable and sustainable sources $[1,8]$. Catalytic transformation is one of the pathways to synthesize biodiesel. $\mathrm{NaOH}$ and $\mathrm{KOH}$ have been reportedly utilized in the transesterification process as homogeneous base catalysts $[89,90]$. However, the difficulty in separation and corrosiveness of the equipment are limiting factors of these materials. In their separate works reported, base catalysts outperformed acid catalysts, according to Demirbas et al. and Kazemifard et al. [91, 92]. Short reaction times and low molar ratios are common characteristics of these catalysts [93, 94], but unfortunately, homogeneous catalysts have many limitations. Interestingly, efficient reactive solid catalysts, such as zeolite and nanomaterials, have been employed to beat down the limitations of heterogeneous catalysis; these catalysts have a shorter reaction time and can react at low molar ratios. [95, 96].

Titanate nanotube materials are nanomaterials that recently caught attention owing to their low toxic feature, cost-effectiveness, and higher aspect ratio when related to other suitable various morphologies [97-99]. Of a recent, many researchers whose works are related to the synthesis of biofuels have employed these one-dimensional (1D) titanate and titanatebased nanostructured materials in the production of biodiesel [100-102]. In their recent work, Zaki and his co-workers employed simple, low-cost, and hydrothermally obtained sodium titanate nanotubes (STNTs) as a sustainable and environmentally benign solid catalyst in the transesterification of pure and used cooking oils (UCO) using diverse experimental parameters for investigation (such as molar ratio, temperature, catalyst weight, and time). 
The titanate nanotube catalysts demonstrated significant high performance based on the adopted experimental parameters. At a relatively low reaction time of $2 \mathrm{~h}$, the temperature of $353 \mathrm{~K}$ the biodiesel yield reported was found to be 95.9 percent. Furthermore, the author equally investigated the catalysts for the UCO conversion and interestingly obtained high activity with yields of 96.0,96.0, and $93.58 \%$ for the first, second, and third uses of oil, respectively. To economize the synthesis routes, they recycled methanol for subsequent use in another transesterification activity, and they equally record a yield of 91 percent of biodiesel. Furthermore, the transesterification findings were presented using a pseudo-first-order kinetic model [103].

Observation from HRTEM micrographs showed the tubular structure of the as-prepared titanate materials with an average diameter of $5.37 \mathrm{~nm}$ and tube lengths (from 50 to $80 \mathrm{~nm}$ ) (Fig. 10) [104]. According to FT-IR spectrum of the prepared TNTs, the Ti-O stretching vibration was allocated to the band seen at $901 \mathrm{~cm}^{-1}$ (Fig. 11). The O-H stretching

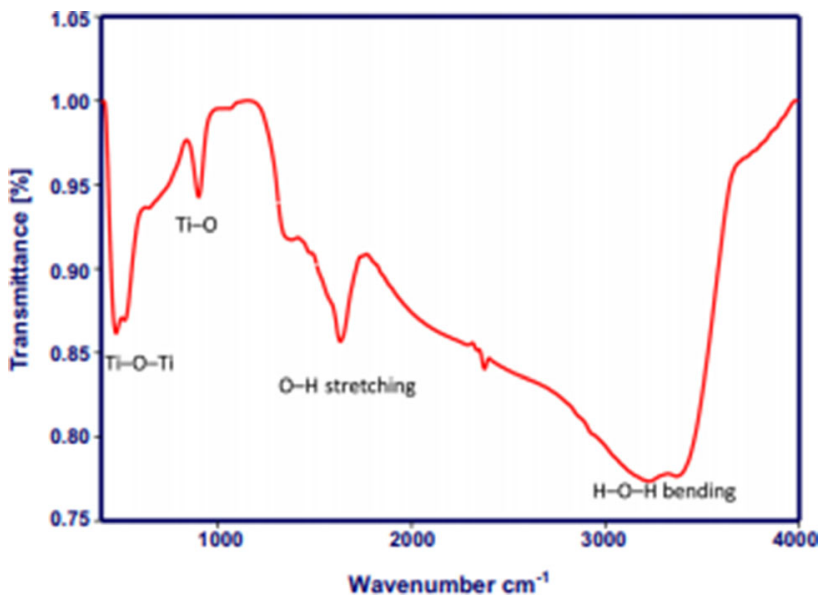

Figure 11 FT-IR spectrum of sodium titanate nanotubes (STNTs) [103].

vibration and the $\mathrm{H}-\mathrm{O}-\mathrm{H}$ bending vibration are due to the large bands found at $1633 \mathrm{~cm}^{-1}$ and $3400-3200 \mathrm{~cm}^{-1}$ respectively, suggesting the presence of water molecules in the prepared titanate nanostructured materials.
Figure 10 a HRTEM image of sodium titanate nanotubes (STNTs). b FESEM monographs of sodium titanate nanotubes (STNTs) [103].

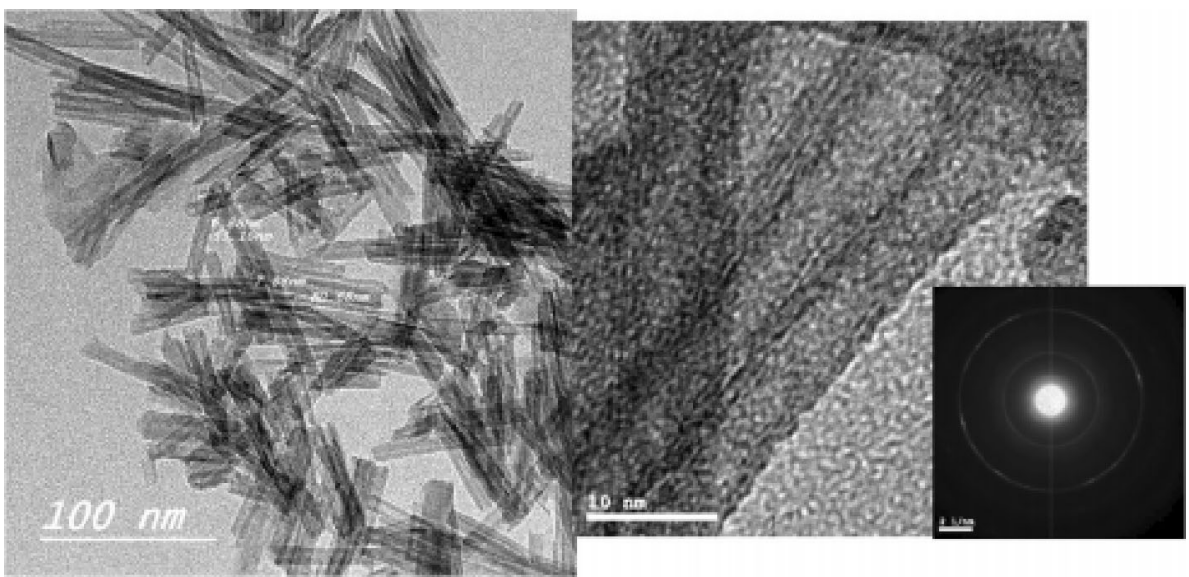

(a)

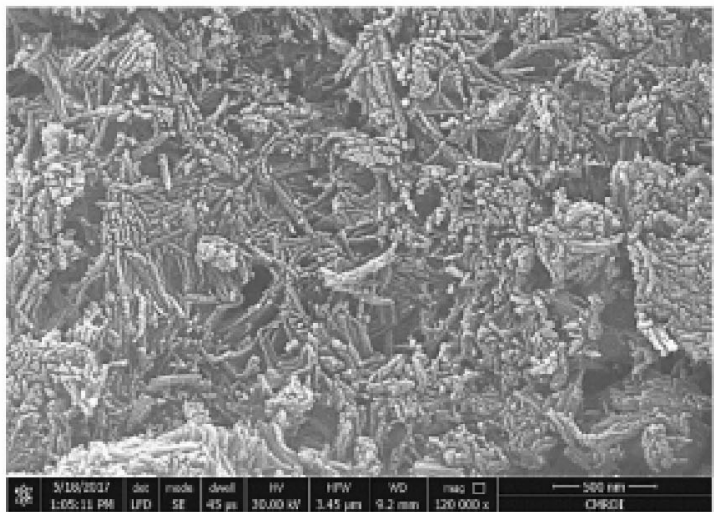

(b) 
The pseudo-first-order reaction (see Eq. 3) was adopted for simplifying the reaction kinetics of the formation of methyl esters from waste frying oil used as precursors. However, the rearrangement of Eq. 3 related to the fractional conversion ( $\mathrm{xA}$ ) of the obtained biodiesel and its integration yields is represented in Eq. (4). The experimental (xA) values were fitted using Eq. (5), and the nonlinear regression of this equation yields the regression coefficient $(\mathrm{R} 2=0.94)$ and $\mathrm{k}_{1}=0.0213 \mathrm{~min}^{-1}$, which confirms a pseudo-first-order reaction

$-r_{A}=\frac{d C_{A}}{d t}$

$\frac{d C_{A}}{d t}=k_{1}\left(1-x_{A}\right)$

$x_{A}=\left(1-e^{-\left(k_{1} t+c\right)}\right)$

where CA represents the molar concentration of oil, $\mathrm{k}_{1}$ stands for the pseudo-first-order rate constant, while c means integration constant [103].

The titanate nanostructured materials with their functional identified characteristic properties are given in Table 3.

\section{Bio-based economy-catalysis and renewable feedstocks: a quest for integrated solutions to meet sustainability!}

The idea of the bio-economy as a sustainable development method has positively impacted both environmental and energy sectors. As a result, we have witnessed interesting evidence of renewable and sustainable materials manufactured with benign environmental consciousness [105]. Today, as we already know, almost the entire globe is experiencing environmental pollution in one way or another, such as global warming emanating from uncontrollable exploitation and utilization of non-renewable petroleum-derived fuels and the buildup of dangerous gases in the stratosphere $[6,7,105]$. There is a need to switch toward practicing bio-based economy (BBE) that comes with sustainability and environmental benefits. The primary goal of bio-based economy (BBE) can only be sustained via clear green credentials of sustainable catalysis and utilization of renewable feedstocks (which do not compete with foods and feeds) following the provision of green

Table 3 Summary of the unique characteristic features of novel titanate nanostructured materials, the synthesized products, and their applications

\begin{tabular}{|c|c|c|c|c|}
\hline $\begin{array}{l}\text { Type of titanate } \\
\text { nanostructured } \\
\text { catalyst }\end{array}$ & $\begin{array}{l}\text { Characteristic properties } \\
\text { responsible for their activity }\end{array}$ & Synthesized products & Industrial applications of the products & Ref \\
\hline PTNT & $\begin{array}{l}\text { Presence of both Lewis acid sites } \\
\text { and Bronsted acid sites. The acid } \\
\text { strength }\end{array}$ & $\begin{array}{l}\text { o-benzyl toluene and p-benzyl } \\
\text { toluene }\end{array}$ & $\begin{array}{l}\text { Applicable in biorefinery for the } \\
\text { synthesis of value-added chemicals }\end{array}$ & [71] \\
\hline PTNT & $\begin{array}{l}\text { Presence of both Lewis acid sites } \\
\text { and Bronsted acid sites. Higher } \\
\text { acid strength }\end{array}$ & Fuel precursors & $\begin{array}{l}\text { Applicable in biorefinery for the } \\
\text { synthesis of biofuels }\end{array}$ & {$[73]$} \\
\hline HTiNTs & $\begin{array}{l}\text { Presence of both Lewis acid sites } \\
\text { and Bronsted acid sites. The acid } \\
\text { strength }\end{array}$ & Fuel precursors & $\begin{array}{l}\text { Applicable in biorefinery for the } \\
\text { synthesis of biofuels }\end{array}$ & {$[76]$} \\
\hline HTNT & $\begin{array}{l}\text { Presence of both Brönsted and } \\
\text { Lewis acid sites }\end{array}$ & $\begin{array}{l}\text { Bis(hydroxyethyl)terephthalate } \\
\text { (BHET) }\end{array}$ & $\begin{array}{l}\text { It is a value-added monomer applicable } \\
\text { in biorefinery }\end{array}$ & {$[80]$} \\
\hline $\begin{array}{l}\mathrm{H}_{2} \mathrm{Ti}_{3} \mathrm{O}_{7} \text { (HTO- } \\
\quad \mathrm{RT}) \\
\mathrm{H}_{2} \mathrm{Ti}_{3} \mathrm{O}_{7}(\mathrm{HTO}- \\
\quad \mathrm{HT})\end{array}$ & $\begin{array}{l}\text { Presence of both Lewis acid sites } \\
\text { and Bronsted acid sites }\end{array}$ & $\begin{array}{l}\text { Synthesis of } \\
\text { 5-(hydroxymethyl)furfural } \\
\text { (HMF) }\end{array}$ & $\begin{array}{l}\text { Useful in the synthesis of various value- } \\
\text { added products (VAPs) e.g., Levulinic } \\
\text { acid (LA) in biorefinery }\end{array}$ & [85] \\
\hline HTNT & $\begin{array}{l}\text { Both Lewis acid sites, and } \\
\text { Bronsted acid sites }\end{array}$ & $\begin{array}{l}\text { Fuel precursors/value-added } \\
\text { chemicals (VACs) }\end{array}$ & $\begin{array}{l}\text { Applicable in biorefinery synthesis of } \\
\text { biofuels }\end{array}$ & {$[8]$} \\
\hline
\end{tabular}


chemistry's principles and sustainable development goals (SDGs) [1, 6, 7, 106].

Moreover, the foundation of this economy is the efficient use of biorefinery innovatively to maximally transform sustainable and renewable feedstocks to biofuels and chemicals of high value. This synthesis pathway can minimize waste streams partly, while a carbon-negative cycle is guaranteed $[1,6,7,106]$. Therefore, from an analytical viewpoint, achieving SDGs and the demands of the contemporary without conceding the capacity of upcoming generations to achieve their demands require commitment with policy backing and action taking steps to attain maximum human benefits with the consciousness of a healthy environment without further degradation $[105,106,108]$. Graedel E.T, in his submission, pointed that sustainability comprises three major components (namely societal, ecological, and economic), which were also called 3Ps of sustainability (where 3Ps means $\mathrm{P}=$ People; $\mathrm{P}=$ Planet; $\mathrm{P}=$ profit). According to his study, sustainable technology must possess a consciousness of two major conditions to be sustainable indeed: (i) responsible use of natural resources at rates that do not further cause reckless depletion in supplies over the long term and (ii) the generated residues should not further contribute to environmental degradation; therefore, the natural environment must be considered in the plan [107]. Getting this goal of bio-economy achieved, utilization of sustainable solid catalysts and biomass is inevitable. The main precursor of NaTNT and PTNT, an inexpensive and simple solid acid catalyst, has been described as a stable, robust, recyclable, and highly effective catalyst. Titanium is the ninth most common element on the planet, as we all know. In the meantime, it is the second most common transition metal. $\mathrm{TiO}_{2}$ is a famous corrosion-resistant, eco-friendly, and ecologically safe substance [8]. Therefore, it is a promising material in biomass-related transformations.

\section{Cost analysis of titanate nanostructured materials}

Giving attention to upgrading layered titanate synthesis to a commercial status. In 2020, even with existing novel covid-19, the volume of titanium sponge in China was estimated to be about 0.14 million metric tons in production. Actually, the production volume of titanium sponge has been reported increasing in the last few years based as demand rise annually [108]. Through continuous development in titanium metals which are suitable for many applications in aviation industry. According to recent reports, the growth in the use of these materials are likely to shoot up with usage of titanium for next-generation aircraft, consumption of titanium mill products with $4.9 \%$ annually reported in year 2019 [109]. In the global production report of metallic titanium sponge, more than 200,000 metric tons per year have been recorded. The major ores obtainable (i.e., anatase or rutile $\mathrm{TiO}_{2}$ and ilmenite $\left(\mathrm{FeTiO}_{3}\right)$ ) have been said to be above 7 million metric tons annually as a result of their tremendous use in various applications. The countless number of applications of $\mathrm{TiO}_{2}$ apart from reduction to titanium metal has also been said to be responsible for the rise in annually production. As already reported, layered titanates can be produced directly from $\mathrm{TiO}_{2}$ costeffectively (below $2 \mathrm{USDkg}^{-1}$ ); therefore, they rank among the potentially cheapest commercially available nanomaterials. $\mathrm{Na}_{2} \mathrm{Ti}_{3} \mathrm{O}_{7}$, sodium metatitanate with registration number of CAS: 12034-36-05 and is available commercially from all major laboratory chemical vendors. However, major fine chemical prices are in the range of $3000 \mathrm{USDkg}^{-1}$.

From market analysis, it has been shown that layered titanate nanomaterials are gaining global attention owing to their various applications. It is abundance in nature and as well as demand-based market materials as a result of their suitability as potential precursors in nanotechnology-based applications to address environmentals issues ranges from being used in nanoremediation, aerospace to renewable fuels synthesis, it has attracted huge number of buyers globally. Titanate nanotubes are sold as CAS 12026-28-7 (metatitanic acid) by commercial nanotube suppliers (e.g., Auro-Science Ltd in Hungary, Smart Metal Limited, Xuzhou Jiechuang New Material Technology Co, JinZhongYan New Material Technology Co. and Hongwu International Group Ltd. in China), with an estimated combined capacity of 4000 metric tons per year [110, 111]. However, the prices range from 150 to $250 \mathrm{USDkg}^{-1}$ for pristine titanate nanotubes, while it may be far more when the materials are functionalized and or modified in nature according to specific demand. Titanate nanotubes and nanowires stand out from the sea of diverse nanomaterials developed in the past twenty 
years because it is actually feasible to scale up their synthesis and produce them on a commercial scale at reasonable cost [112-114].

This is possible because of the following advantages: (a) They are obtained with close to $100 \%$ yield as the $\mathrm{TiO}_{2}$ raw material recrystallizes in the alkaline hydrothermal process. Conversion is $100 \%$ because titanates are thermodynamically favored over $\mathrm{TiO}_{2}$ at those experimental conditions, and there are no byproducts or alternative products. (b) The synthesis method is robust. Minor variations in reaction temperature and time or a change in the $\mathrm{TiO} 2$ supplier will not affect the product quality severely. (c) The process is non-explosive, water based and has a very small environmental footprint. The only waste that leaves the plant is the brine formed upon the neutralization of $\mathrm{Na}_{2} \mathrm{Ti}_{3} \mathrm{O}_{7}$ by diluted hydrochloric acid. (d) Equipment wise, the core-layered titanate nanomaterial synthesis technology is very similar to that of synthetic zeolite production. Therefore, existing zeolite plants could be directly employed for the synthesis of titanate nanomaterial with little cost, and thus supply will likely be able to keep up with growing demand in the foreseeable future [48].

\section{Conclusions and perspectives}

From the reported literature, it is evident that protonated titanate nanotubes are competent promising solid acid catalysts for the manufacture of biofuel's precursors and/or value-added substances. They have been found useful in various synthesis reaction procedures such as aldol condensation reaction of methyl benzaldehydes with bio-derived ketones for the preparation of both biodiesel and jet fuel precursors, HAA of 2-methyl furan (2-MF) and n-butanal, Friedel-Crafts alkylation of toluene with benzyl chloride, aldol condensation of benzaldehyde and cyclohexanone, depolymerization of PET, depolymerization of PET (virgin and post-consumer), isomerization of glucose/ fructose, etc. All of the reactions recorded with protonated titanate nanotubes as solid acid catalysts showed impressive catalytic efficiency from the catalytic materials. These catalytic performances were ascribed to their morphology, superior specific surface area, additional acid site, and acid strength.

The hydrothermal method, a simple, cost-effective, and environmentally benign, has been employed in the synthesis; using this type of sustainable technique has equally pronounced the bio-based system economy owing to its superiority to stoichiometry features of the traditional homogenous catalytic system. Considering the recent global warming reports due to excessive exploration of non-renewable resources, the urgent need to source an alternative is imminent since biomass is abundant and equally renewable, and suitable for fuels and value-added product production. Therefore, utilization of bio-derived resources has come to position our environment toward sustainability paths with responsible materials.

The sensitization and action to switch toward biobased economic (BBE) that comes with sustainability and environmental benefits are required, especially to realize sustainable energy and fuel as the potential to meet energy needs is huge with the utilization of biomass and waste streams.

However, the limitation of this study is that we report the sustainability and cost-effectiveness based on the experimental parameters employed in the synthesis of each morphology owing to lack of study on these areas. Likewise, reuse/recyclability of these materials poses no issue when compared with homogeneous catalysts and no issues of equipment corrosion. On the other hand, in order to fully establish the wholistic sustainability and cost-effectiveness of the titanate materials and the system reported in general, there is need for further studies on financial cost analysis and life cycle assessment as these aspects really demand urgent attention since environmental consideration is very important in chemical synthesis and analysis to better position our environment in the recommendation of sustainable development goals (SDGs) as spelt out by United Nations and pathway of Green/Sustainable Chemistry.

In a nutshell, we believe that current and future developments, from an industrial vantage point, chemical synthesis with the consciousness of a healthy environment holds the key to achieve a desired sustainable bio-based circular economy. Efficient combination of Green Chemistry's values \#7 (use of renewable feedstocks), \#9 (use of catalyst), and Sustainable Development Goals (SDGs) \#7(affordable and clean energy; ensure access to inexpensive, reliable, sustainable, and new energy) is inevitable to accomplish bio-economy. 


\section{Acknowledgements}

The authors are thankful to Mrs. Bukola Aderemi, Master Daniel Adeleye, Ms. Eunice Adeleye and Mr. \& Mrs. Adeleke Adeleye for their sacrifices, encouragements and kind supports toward successful completion of this study.

\section{Author contribution}

ATA involved in conceptualization, methodology, resources, data curation, investigation, formal analysis, software, writing an original draft, writing-review \& editing, and project administration. KJ involved in investigation, software, writing-review, and validation and editing the manuscript. PGA involved in investigation and writing-review \& editing. AAA involved in writing-review \& editing and validation and supervision. OOB involved in writing-review \& editing and validation.

\section{Funding}

This study receives no specific grant from any funding agencies in the public, commercial or not-forprofit sectors.

\section{Declarations}

Conflict of interest Authors declare no conflict of interest for the study.

\section{References}

[1] Adeleye AT, Akande AA, Odoh CK, Philip M, Fidelis TT, Amos PI, Banjoko OO (2021) Efficient synthesis of biobased activated carbon (AC) for catalytic systems: a green and sustainable approach. J Ind Eng Chem 96:59-75. h ttps://doi.org/10.1016/j.jiec.2021.01.044

[2] Jiang R, Liu G, Zhang X (2013) Thermal cracking of hydrocarbon aviation fuels in regenerative cooling microchannels. Energy Fuels 27(5):2563-2577. https://oi. org/10.1021/ef400367n

[3] Today in Energy https://www.eia.gov/todayinenergy/detail. php?id=43216\# accessed on February 6th,2021.

[4] Biofuel production in China (2019) https://blog.technavio.c $\mathrm{om} / \mathrm{blog} /$ biofuel-production-china-expected-top-8-billion-li ters-2019 accessed on February 10th, 2021).
[5] Pfaltzgraff LA, Clark JH (2014) Green chemistry, biorefineries and second generation strategies for re-use of waste: an overview. In: Waldron $\mathrm{K}$ (ed) Advances in biorefineries. Woodhead Publishing, UK, pp 3-33

[6] Adeleye AT, Louis H, Akakuru OU, Joseph I, Enudi OC, Michael DP (2014) Review on the conversion of levulinic acid and its esters to various useful chemicals AIMS. Energy 7(2):165. https://doi.org/10.3934/ENERGY.2019.2. 165

[7] Adeleye AT, Odoh CK, Enudi OC, Banjoko OO, Osigbeminiyi OO, Toluwalope OE, Louis H (2020) Sustainable synthesis and applications of polyhydroxyalkanoates (PHAs) from biomass. Process Biochem 96:174. https://d oi.org/10.1016/j.procbio.2020.05.032

[8] Timothy AA, Han F, Li G, Xu J, Wang A, Cong Y, Li N (2020) Synthesis of jet fuel range high-density dicycloalkanes with methyl benzaldehyde and acetone sustain. Energy Fuels 4:5560. https://doi.org/10.1039/D0SE01110J

[9] Ran YL, Wang HQ, Xiao Y, Liu G, Li A, Wang X, Wang Y, Cong TZ, Li N (2021) Synthesis of bio-based methylcyclopentadiene via direct hydrodeoxygenation of 3-methylcyclopent2-enone derived from cellulose. Nat Commun 12:46. https://doi.org/10.1038/s41467-020-20264-3

[10] Oesper RE (1948) Alwin mittasch. J Chem Educ 25:532

[11] Kasuga TH, Hoson M, Sekino A, Niihara T (1998) Formation of titanium oxide nanotube. Langmuir 14(1998):3160-3163

[12] Kasuga TH, Hoson M, Sekino A, Niihara T (1999) Titania nanotubes prepared by chemical processing. Adv Mater 11:1307-1311

[13] Kitano M, Kondo JN, Hayashi S, Hara M (2010) Protonated titanate nanotubes as solid acid catalyst. J Am Chem Soc 132(19):6622-6623. https://doi.org/10.1021/ja $100435 \mathrm{w}$

[14] Mokhtar SM, Soon CF, Nafarizal N, Faridah AB, Suriani AB, Mamat MH, Shimomura M, Murakami K (2018) Fabrication and characterization of rutile-phased titanium dioxide (TiO2) nanorods array with various reaction times using one step hydrothermal method. Optik-Int. J Light Electron Optics 154:510-515

[15] Camposeco R, Hinojosa-Reyes M, Castillo S, Nava N, Camposeco RZ (2021) Synthesis and characterization of highly dispersed bimetallic Au-Rh nanoparticles supported on titanate nanotubes for $\mathrm{CO}$ oxidation reaction at low temperature. Environ Sci Pollut Res 28:10734-10748. h ttps://doi.org/10.1007/s11356-020-11341-7

[16] Rao B, Torabi A, Varghese O (2016) Anodically grown functional nanotubes and applications. MRS Comm 6(4):375-396. https://doi.org/10.1557/mrc.2016.46 
[17] Ghicov A, Macak JM, Tsuchiya H, Kunze J, Haeublein V, Kleber S, Schmuki P (2006) TiO2 nanotube layers: dose effects during nitrogen doping by ion implantation. Chem Phy Lett 419:426-429. https://doi.org/10.1016/j.cplett.200 5.11 .102

[18] Xiang PZand Jiahua N (2019). Surface properties and bioactivity of $\mathrm{TiO}_{2}$ nanotube array prepared by two-step anodic oxidation for biomedical applications R. Soc open sci. 6:18:194 8181948

[19] Abdullah M, Kamarudin SK (2017) Titanium dioxide nanotubes (TNT) in energy and environmental applications: an overview. Renew Sust Energ Rev 76:212-225. https://d oi.org/10.1016/j.rser.2017.01.057

[20] Arifin K, Yunus RM, Minggu LJ, Kassim MB (2020) Improvement of $\mathrm{TiO} 2$ nanotubes for photoelectrochemical water splitting: Review. J. Hydrog. Energy, Int. https://oi. org/10.1016/j.ijhydene.2020.11.063

[21] Kukovecz Á, Kordás K, Kiss J, Kónya Z (2016) Atomic scale characterization and surface chemistry of metal modified titanate nanotubes and nanowires. Surf Sci Rep 71(3):473-546. https://doi.org/10.1016/j.surfrep.2016.06. 001

[22] Zhang Y, Jiang Z, Huang J, Lim LY, Li W, Deng J, Chen Z (2015) Titanate and titania nanostructured materials for environmental and energy applications: a review. RSC Adv 5(97):79479-79510. https://doi.org/10.1039/c5ra11298b

[23] Lee K, Mazare A, Schmuki P (2014) One-dimensional titanium dioxide nanomaterials: nanotubes. Chem Rev 114(19):9385-9454. https://doi.org/10.1021/cr500061m

[24] Giannakoudakis DA, Chatel G, Colmenares JC (2019) Mechanochemical forces as a synthetic tool for zero- and one-dimensional titanium oxide-based nano-photocatalysts. Top Curr Chem. https://doi.org/10.1007/s41061-019-02623

[25] Ameur N, Bachir R (2020) Study of 1D titanate-based materials -new modification of the synthesis procedure and surface properties-recent applications. ChemSelect 5(3):1164-1185. https://doi.org/10.1002/slct.201904539

[26] Sudarsanam P, Li H, Sagar TV (2020) TiO2-based watertolerant acid catalysis for bio-derived fuels and chemicals. ACS Catal. https://doi.org/10.1021/acscatal.0c01680

[27] Sudarsanam P, Zhong R, Van den Bosch S, Coman SM, Parvulescu VI, Sels BF (2018) Functionalised heterogeneous catalysts for sustainable biomass valorisation. Chem Soc Rev 47:8349-8402. https://doi.org/10.1039/c8c s00410b

[28] Feynman RP, There's plenty of room at the bottom., Am Phy Soc 1959.
[29] Brune HB, Bromann KB, Kern K (1998) Self-Organized growth of nanostructures arrays on strain-relief patterns. Nat 394:451-453. https://doi.org/10.1038/28804

[30] Roduner EI, Size matters: why nanomaterials are different, (2006) Chem Soc Rev 35:583-592. https://doi.org/10.1039/ B502142C

[31] Kolahalam LA, Kasi Viswanath IV, Diwakar BS, Govindh B, Reddy V, Murthy YLN (2019) Review on nanomaterials: synthesis and applications. Mater Today. https://doi. org/10.1016/j.matpr.2019.07.371

[32] Gong D, Ho WCJ, Tang Y, Tay Q, Lai Y, Highfield JG, Chen Z (2012) Silver decorated titanate/titania nanostructures for efficient solar driven photocatalysis. J Solid State Chem 189:117-122. https://doi.org/10.1016/j.jssc.2011.11. 036

[33] Zhang S, Yang D, Jing D (2014) Enhanced photodynamic therapy of mixed phase $\mathrm{TiO}$ (B)/anatase nanofibers for killing of HeLa cells. Nano Res 7:1659-1669. https://doi. org/10.1007/s12274-014-0526-8

[34] Bavykin DV (2009) Elongated titanate nanostructures and their applications. Eur J Inorg Chem 8:977-997. https://doi. org/10.1002/ejic.200801122

[35] Wang BL, Chen Q, Wang RH, Peng LM (2003) Synthesis and characterization of K2Ti6O13 nanowires. Chem Phy Lett. 376:726-731

[36] Anastas J, Warner P (1998) Green chemistry: Theory and Practice. UK Oxford Univ. Press, Oxford

[37] Xiao T, Yabushita M, Nishitoba T, Osuga R, Yoshida M, Matsubara M, Maki S, Kanie K, Yokoi T, Cao W, Muramatsu A (2021) Organic structure-directing agent-free synthesis of mordenite-type zeolites driven by al-rich amorphous aluminosilicates. ACS Omega 6(8):5176-5182. https://doi.org/10.1021/acsomega.0c05059

[38] Corma A (1995) Inorganic solid acids and their use in acidcatalyzed hydrocarbon reactions. Chem Rev 95:559-614. h ttps://doi.org/10.1021/cr00035a006

[39] Gupta P, Paul S (2014) Solid acids: green alternatives for acid catalysis. Cat Today 236:153-170. https://doi.org/10. 1016/j.cattod.2014.04.010

[40] Yu Z, Huang X, Xun S, He M, Zhu L, Wu L, Li H (2020) Synthesis of carbon nitride supported amphiphilic phosphotungstic acid based ionic liquid for deep oxidative desulfurization of fuels. J Mol Liq 308:113059. https://doi. org/10.1016/j.molliq.2020.11305913059

[41] Hideshi (2010) Solid acid catalysts: roles in chemical industries and new concepts. Top Catal 53:432-438. http s://doi.org/10.1007/s11244-010-9469-9

[42] Shandilya M, Rai R, Singh J (2016) Review: hydrothermal technology for smart materials. Adv Appl Ceram 
115:354-376. https://doi.org/10.1080/17436753.2016. 1157131

[43] Yamakov V, Phillpot S, Mukherjee A, Gleiter H (2004) Deformation-mechanism map for nanocrystalline metals by molecular-dynamics simulation. Nature Mater 3:43-47. h ttps://doi.org/10.1038/nmat1035

[44] Gan YX, Jayatissa AH, Yu Z, Chen X, Li M (2020) Hydrothermal Synth of Nanomater J Nanomater 2020:1-3. https://doi.org/10.1155/2020/8917013

[45] Kwang H, Jikang J, Dong-Jin L, Yongju P, Changhee L, Byung L, Seunghun YH, H, (2015) Bi-Assisted CdTe/CdS nanostructure growth for photoconductive applications. Nano Scale lett 10:1-7. https://doi.org/10.1186/s11671-01 5-1037-6

[46] Tuncolu İG, Aciksari C, Suvaci E, Ozel SI, Rembeza ES, Rembeza TVS (2015) Synthesis of $\mathrm{Zn} 2 \mathrm{SnO} 4$ powders via hydrothermal method for ceramic targets. J Eur Ceram Soc 35:3885-3892. https://doi.org/10.1016/j.jeurceramsoc.201 5.07 .003

[47] Su B, Button TW, Ponton CB (2004) Control of the particle size and morphology of hydrothermally synthesised lead zirconate titanate powders. J Mater 39:6439-6447. https://d oi.org/10.1023/B:JMSC.0000044881.35754.ea

[48] Monteiro WF, dos Santos CAB, Hoffmann MS, Carone CLP, Einloft SMO, de Souza MO, Ligabue RA (2019) Modified titanate nanotubes for the production of novel aliphatic polyurethane nanocomposites. Polym Compos 40:2292-2300. https://doi.org/10.1002/pc.25038

[49] Kordás M, Mohl Z, Kónya, \& Kukovecz A, (2015) Layered titanate nanostructures: perspectives for industrial exploitation. Transl Mater Res 2(1):015003. https://doi.org/ 10.1088/2053-1613/2/1/015003

[50] Ameur N, Bachir R (2020) Study of 1D titanate-based materials -new modification of the synthesis procedure and surface properties-recent applications. ChemSelect 5:1164-1185. https://doi.org/10.1002/slct.201904539

[51] Bavykin DV, Friedrich JM, Lapkin AA, Walsh FC (2006) Stability of aqueous suspensions of titanate nanotubes. Chem Mater 18:1124-1129

[52] Papa A-L, Millot N, Saviot L, Chassagnon R, Heintz O (2009) Effect of reaction parameters on composition and morphology of titanate nanomaterials. J Phys Chem C 113:12682-12689

[53] Wong CL, Tan YN, Mohamed AR (2011) A review on the formation of titania nanotube photocatalysts by hydrothermal treatment. J Environ Manage 92:1669-1680

[54] Bavykin DV, Walsh FC (2007) Kinetics of alkali metal ion exchange into nanotubular and nanofibrous titanates. J Phys Chem C 111:14644-14651
[55] Cheng G, Jun D, Xiuyun L, Zhenjie Y, Jiansong M, Wenqian Q, Kai Z, Jin Y (2018) Nanomater 8(9):683. https://d oi.org/10.3390/nano8090683

[56] Nicolini JV, de Resende NS, Ferraz HC (2014) Adsorption of horseradish peroxidase onto titanate nanowires. J Chem Technol Biotechnol 90:739-746. https://doi.org/10.1002/jc tb.4369

[57] Bo A, Zhan H, Bell J, Zhu H, Gu Y (2014) Mechanical bending properties of sodium titanate $\left(\mathrm{Na}_{2} \mathrm{Ti}_{3} \mathrm{O}_{7}\right)$ nanowires. RSC Adv 4:56970-56976. https://doi.org/10.1039/c $4 \mathrm{ra} 11753 \mathrm{k}$

[58] Dong W, Cogbill A, Zhang T, Ghosh S, Tian ZR (2006) Multifunctional, catalytic nanowire membranes and the membrane-based 3D devices. J Phys Chem A 110:16819-16822. https://doi.org/10.1021/jp0637633

[59] Tsumura T, Sogabe K, Kiyo T, Toyoda M (2011) Fabrication of titanate nanowires with different dimensions. Mater Lett 65:2322-2325. https://doi.org/10.1016/j.matlet.2011.0 5.028

[60] Kukovecz A, Hodos M, Horváth E, Radnóczi G, Kónya Z, Kiricsi I (2005) Oriented crystal growth model explains the formation of titania nanotubes. $\mathrm{J}$ Phys Chem B 109(2005):17781-17783. https://doi.org/10.1021/ jp054320m

[61] Liu R, Yang WD, Chueng HJ, Ren BQ (2015) Preparation and application of titanate nanotubes on dye degradation from aqueous media by UV irradiation. J Spectrosc 2015:1-9. https://doi.org/10.1155/2015/680183

[62] S Uchida, ChibaR, Tomiha M, Masaki N and Shirai M (2002). Application of titania nanotubes to a dye-sensitized solar cell Electrochemistry 70418420

[63] Qamar M, YoonC R, Oh HJ, Kim DH, Jho JH, LeeK S, LeeW J, Lee HG, Kim SJ (2006) Effect of post treatments on the structure and thermal stability of titanate nanotubes. Nanotechnology 17:5922-5929

[64] LeeC-K W-C, Lyu M-D, Juang L-C, Liu S-S, Hung S-H (2007) Effects of sodium content and calcination temperature on the morphology, structure and photocatalytic activity of nanotubular titanates. J Colloid Interface Sci 316:562-569

[65] Morgado E Jr, de Abreu MAS, Moure GT, Marinkovic BA, Jardim PM, AraujoA S (2007) Effects of thermal treatment of nanostructured trititanates on their crystallographic and textural properties. Mater Res Bull 42:1748-1760

[66] Morgado E Jr, de Abreu MAS, Pravia ORC, Marinkovic BA, Jardim PM, Rizzo FC, AraujoA S (2006) A study on the structure and thermal stability of titanate nanotubes as a function of sodium content. Solid State Sci 8:888-900

[67] ZhangW ZhouW, WrightJ H, KimY N, LiuXiaoX D (2014) Mn-Doped TiO2 nanosheet-based spheres as anode 
materials for lithium-ion batteries with high performance at elevated temperatures ACS Appl. Mater Interfaces 6:7292-7300

[68] SongX C, ZhengY F, Yin HY, Cao GS (2005) Synthesis and characterization of transition element substituted titanate nanotubes. Acta Phys Chim Sin 21:1076-1080

[69] HeX, Wang Z, HirataA, Gu L, Chen M and DuanX 2011 Modulated Na2 Ti4 O9 : Zr nanobelt via site-specific $\mathrm{Zr}$ doping Appl. Phys. Express 4085003

[70] Bavykin DV, Friedrich JM, Walsh FC (2006) Protonated Titanates and $\mathrm{TiO} 2$ nanostructured materials: synthesis, properties, and applications. Adv Mater 18:2807-2824. h ttps://doi.org/10.1002/adma.200502696

[71] Kitano MW, Nakajima K, Hayashi S, Miyazaki S, Kobayashi H, Hara M (2013) Protonated titanate nanotubes with lewis and brønsted acidity: relationship between nanotube structure and catalytic activity. Chem Mater 25:385-393. https://doi.org/10.1021/cm303324b

[72] Takagaki A, Sugisawa M, Lu D, Kondo JN, Hara M, Domen K, Hayashi S (2003) Exfoliated nanosheets as a new strong solid acid catalyst. J Am Chem Soc 125(18):5479-5485. https://doi.org/10.1021/ja034085q

[73] Ogasawara Y, Uchida S, Yamaguchi K, Mizuno N (2009) A tin-tungsten mixed oxide as an efficient heterogeneous catalyst for $\mathrm{CC}$ bond-forming reactions. Chem-Chem Eur J 15:4343-4349. https://doi.org/10.1002/chem.200802536

[74] Li S, Li N, Li G, Wang A, Cong Y, Zhang T (2015) Protonated titanate nanotubes as a highly active catalyst for the synthesis of renewable diesel and jet fuel range alkanes. Appl Catal 2015:24-134. https://doi.org/10.1016/j.apcatb. 2015.01.022

[75] Li G, Li N, Li S, Wang A, Cong Y, Wang X, Zhang T (2013) Synthesis of renewable diesel with hydroxyacetone and 2-methyl-furan. ChemComm 49:5727. https://doi.org/ $10.1039 / \mathrm{c} 3 \mathrm{cc} 42296 \mathrm{~h}$

[76] Li G, Li N, Wang Z, Li C, Wang A, Wang X, Cong Y, Zhang $T$ (2012) Synthesis of high-quality diesel with furfural and 2-methylfuran from hemicellulose. Chemsuschem 5(10):1958-1966. https://doi.org/10.1002/cssc.201200228

[77] Sluban M, Cojocaru B, Parvulescu VI, Iskra J, Cerc RK, Umek P (2017) Protonated titanate nanotubes as solid acid catalyst for aldol condensation. J Catal 346:161-169. http s://doi.org/10.1016/j.jcat.2016.12.015

[78] Cosimo ID (2010), Aldol reaction - heterogeneous, in: Encycl. Catal, John Wiley \& Sons Inc., https://doi.org/10. 1002/0471227617.eoc011.

[79] Zaki MI, Hasan MA, Al-Sagheer FA, Pasupulety L(2001), In situ FTIR spectra of pyridine adsorbed on $\mathrm{SiO} 2-\mathrm{A} 12 \mathrm{O} 3$, $\mathrm{TiO} 2, \mathrm{ZrO} 2$ and $\mathrm{CeO} 2$ : general considerations for the identification of acid sites on surfaces of finely divided metal oxides, Colloids Surf. Physicochem. Eng. Asp. 190 261-274, https://doi.org/10.1016/S0927-7757(01)00690-2.

[80] Nicholas JB, Winans RE, Harrison RJ, Iton RE, Curtiss LA, Hopfinger AJ (1992) Ab initio molecular orbital study of the effects of basis set size on the calculated structure and acidity of hydroxyl groups in framework molecular sieves. J Phys Chem 96:10247-10257. https://doi.org/10.1021/j10 0204a029

[81] Lima GR, Monteiro WF, Ligabue R, Santana RM (2017) Titanate nanotubes as new nanostrutured catalyst for depolymerization of pet by glycolysis reaction. Mat Res 20:588-595. https://doi.org/10.1590/1980-5373-mr-20170645

[82] Lima GR, Monteiro WF, Scheid CM et al (2019) Evaluation of sodium/protonated titanate nanotubes catalysts in virgin and post consumer pet depolymerization. Catal Lett 149:1415-1426. https://doi.org/10.1007/s10562-019-0272 4-8

[83] https://www.google.com/url?sa=t\&rct=j\&q=\&esrc=s\&sour $\mathrm{ce}=$ web $\& \mathrm{~cd}=\& \mathrm{cad}=$ rja $\&$ uact $=8 \& \mathrm{ved}=2 \mathrm{ahUKEwi1} 1 \mathrm{O} 2 \mathrm{~B}$ mYbvAhUN8BoKHcgRDP4QFjAAegQIARAD\&url=http s\%3A\%2F\%2Fwww.shokubai.org\%2Ftocat $8 \% 2 \mathrm{Fpdf} \% 2 \mathrm{FP}$ oster\%2FP2097.pdf\&usg=AOvVaw1PvmzAFGoRusG_ifu hU1fv accessed on December $25^{\text {th }}, 2020$.

[84] Ota M, Dwijaya B, Hirota Y, Uchida Y, Tanaka S, Nishiyama N (2016) Synthesis of amorphous TiO2 nanoparticles with a high surface area and their transformation to Li4Ti5O12 nanoparticles. Chem Lett 45(11):1285-1287. h ttps://doi.org/10.1246/cl.160702

[85] Hou Q, Qi X, Zhen M, Qian H, Nie Y, Bai C, Zhang S, Bai $\mathrm{X}$ and Ju M (2021). Green Chem., Biorefinery Roadmap Based on Catalytic Production and Upgrading of 5-hydroxymethylfurfural Green Chem., 23:119-231, https://doi. org/10.1039/D0GC02770G

[86] Bart HJ, Reidetschlager J, SchatkaLehmann, K (1994) Kinetics of esterification of levulinic acid with n-butanol by homogeneous catalysis Ind. Eng Chem Res 33:21-25. h ttps://doi.org/10.1021/ie00025a004

[87] Li J, Li D, Xie J, Liu Y, Guo Z, Wang Q, Lyu Y, Zhou Y, Wang J (2016) Pyrazinium polyoxometalate tetrakaidecahedron-like crystals esterify oleic acid with equimolar methanol at room temperature. J Catal 339:123-134. http s://doi.org/10.1016/j.jcat.2016.03.036

[88] Peyrovi MH, Parsafard N, Peyrovi P (2014) Influence of zirconium addition in platinum-hexagonal mesoporous silica (Pt-HMS) catalysts for reforming of n-heptane. Ind Eng Chem Res 53(37):14253-14262. https://doi.org/10.1021/ie 5024244

[89] Zhou S, Jiang D, Liu X, Chen Y, Yin D (2018) Titanate nanotubes-bonded organosulfonic acid as solid acid catalyst 
for synthesis of butyl levulinate. RSC Adv 8:3657. https://d oi.org/10.1039/c7ra12994g

[90] Tamilalagan A, Singaram J, Rajamohan S (2019) Generation of biodiesel from industrial wastewater using oleaginous yeast: performance and emission characteristics of microbial biodiesel and its blends on a compression injection diesel engine. Environ Sci Pollut Res 26(11):11371-11386. https://doi.org/10.1007/s11356-01904556-w

[91] Wen Z, Yu X, Tu S-T, Yan J, Dahlquist E (2010) Biodiesel production from waste cooking oil catalyzed by $\mathrm{TiO} 2-$ $\mathrm{MgO}$ mixed oxides. Bioresour Technol 101(24):9570-9576. https://doi.org/10.1016/j.biortech.201 0.07 .066

[92] Demirbas A (2008) Comparison of transesterification methods for production of biodiesel from vegetable oils and fats. Energ Convers Manag 49(1):125-130. https://doi.org/ 10.1016/j.enconman.2007.05.002

[93] Kazemifard S, Nayebzadeh H, Saghatoleslami N, Safakish E (2018) Assessment the activity of magnetic $\mathrm{KOH} /$ Fe3O4@A12O3 core- shell nanocatalyst in transesterification reaction: effect of $\mathrm{Fe} / \mathrm{Al}$ ratio on structural and performance. Environ Sci Pollut Res 25(32):32811-32821. h ttps://doi.org/10.1007/s11356-018-3249-7

[94] Yahya NY, Ngadi N, Jusoh M, Halim NAA (2016) Characterization and parametric study of mesoporous calcium titanate catalyst for transesterification of waste cooking oil into biodiesel. Energy Convers Manag 129:275-283. http s://doi.org/10.1016/j.enconman.2016.10.037

[95] González EAZ, García-Guaderrama M, Villalobos MR, Dellamary FL, Kandhual S, Rout NP, Arizaga GGC (2015) Potassium titanate as heterogeneous catalyst for methyl transesterification. Powder Technol 280:201-206. https://d oi.org/10.1016/j.powtec.2015.04.030

[96] Hassani M, Najafpour GD, Mohammadi M, Rabiee M (2014) Preparation, characterization and application of zeolite-based catalyst for production of biodiesel from waste cooking oil. J Sci Ind Res 73:129-133

[97] Madhuvilakku R, Piraman S (2013) Biodiesel synthesis by $\mathrm{TiO} 2-\mathrm{ZnO}$ mixed oxide nanocatalyst catalyzed palm oil transesterification process. Bioresour Technol 150:55-59. h ttps://doi.org/10.1016/j.biortech.2013.09.087

[98] Rashad S, Zaki AH, Farghali AA (2019) Morphological effect of titanate nanostructures on the photocatalytic degradation of crystal violet. Nanomater Nanotechnol 9:84798041882177. https://doi.org/10.1177/ 1847980418821778

[99] Zaki AH, Abdel Hafiez M, El Rouby WMA, El-Dek SI, Farghali AA (2019) Novel magnetic standpoints in
Na2Ti3O7 nanotubes. J Magn Magn Mater 476:207-212. h ttps://doi.org/10.1016/j.jmmm.2019.01.002

[100] Mahmoud MS, Ahmed E, Farghal AA, Zaki AH, Abdelghani EAM, Barakat NAM (2018) Influence of $\mathrm{Mn}, \mathrm{Cu}$, and $\mathrm{Cd}$-doping for titanium oxide nanotubes on the photocatalytic activity toward water splitting under visible light irradiation. Colloid Surf A Physicochem Eng Asp 554:100-109. https://doi.org/10.1016/j.colsurfa.2018.06. 039

[101] Hernández-Hipólito P, García-Castillejos M, Martínez-Klimova E, Juárez-Flores N, Gómez-Cortés A, Klimova TE (2014) Biodiesel production with nanotubular sodium titanate as a catalyst. Catal Today 220-222:4-11. https://doi. org/10.1016/j.cattod.2013.09.003

[102] Mahangani N, Vunain E, Meijboom R, Jalama K (2015) Biodiesel production over $\mathrm{ZnO} / \mathrm{TiO} 2$ catalyst: effect of cosolvent, temperature and reaction time. WCE, 5, Vol II

[103] Salinas D, Guerrero S, Cross A, Araya P, Wolf EE (2016) Potassium titanate for the production of biodiesel. Fuel 166:237-244. https://doi.org/10.1016/j.fuel.2015.10.127

[104] Zaki AH, Naeim AA, EL-Dek, S.I (2019) Sodium titanate nanotubes for efficient transesterification of oils into biodiesel. Environ Sci Pollut Res 26:6388-36400. https://doi. org/10.1007/s11356-019-06602-Z

[105] Trigo HCE (IICA) and Rodríguez A (ECLAC) (2020). The bioeconomy: a catalyst for the sustainable development of agriculture and rural territories in LAC by IICA is under a license Creative Commons License Recognition-Share the same 3.0 IGO (CC-BY-SA 3.0 IGO) (http://creativecomm ons.org/licenses/by-sa/3.0/igo/) Created from the work at www.iica.int. accessed on February $26^{\text {th }}, 2021$.

[106] Goodland R, Ledec G (1987) Neoclassical economics and principles of sustainable development. The World Bank, Washington, DC, Office of Environmental and Scientific Affairs, p 60

[107] Vanholme B, Desmet T, Ronsse F, Rabaey K, Breusegem FV, Mey MD, Boerjan W (2013) Towards a carbon-negative sustainable bio-based economy. Front Plant Sci. http s://oi.org/10.3389/fpls.2013.00174

[108] Sheldon RA (2016) Engineering a more sustainable world through catalysis and green chemistry. J R Soc Interface 13:20160087. https://doi.org/10.1098/rsif.2016.0087

[109] Graedel TE (2002) Green chemistry and sustainable development. In: Clark J, Macquarrie DJ (eds) Handbook of green chemistry and technology. Wiley, New York, NY, pp 56-61

[110] China: titanium sponge production volume $2020 \mid$ Statista $h$ ttps://www.statista.com/statistics/1072591/china-titanium-s ponge-production-volume/ . accessed on 13th June, 2021 
[111] myb1-2016-titaprd-wret.s3-us-west-2.amazonaws.com/assets/palladium/production/atoms/files/n.pdf accessed on $13^{\text {th }}$ June, 2021

[112] Hongwu International Group Ltd www.hwnanomaterial.c om accessed on $15^{\text {th }}$ June, 2021

[113] Auro-Science Ltd http://auroscience.hu accessed on $10^{\text {th }}$ June, 2021
[114] Nanobakt Ltd http://en.nanobakt.hu accessed on $10^{\text {th }}$ June, 2021

Publisher's Note Springer Nature remains neutral with regard to jurisdictional claims in published maps and institutional affiliations. 